\title{
Carbon Nanotubes for Biomedical Applications
}

\author{
Niraj Sinha*, Student Member, IEEE, and John T.-W. Yeow, Member, IEEE
}

\begin{abstract}
Carbon nanotubes (CNTs) have many unique physical, mechanical, and electronic properties. These distinct properties may be exploited such that they can be used for numerous applications ranging from sensors and actuators to composites. As a result, in a very short duration, CNTs appear to have drawn the attention of both the industry and the academia. However, there are certain challenges that need proper attention before the CNTbased devices can be realized on a large scale in the commercial market. In this paper, we report the use of CNTs for biomedical applications. The paper describes the distinct physical, electronic, and mechanical properties of nanotubes. The basics of synthesis and purification of CNTs are also reviewed. The challenges associated with CNTs, which remain to be fully addressed for their maximum utilization for biomedical applications, are discussed.
\end{abstract}

Index Terms-Biomedical applications, multiwalled nanotubes, single-walled nanotubes.

\section{INTRODUCTION}

$\mathbf{I}$ $\mathrm{N}$ RECENT years, miniaturized products have become increasingly dominant in every aspect of life. The benefits of having smaller components, and hence a device with enhanced capabilities and functionalities, are obvious from the following engineering perspectives: smaller systems tend to move more quickly than larger systems because of lower inertia of mass, the minute sizes of small devices encounter fewer problems in thermal distortion and vibration, and they consume less power [1]. Because of these advantages, miniaturization of systems and devices has become an active area of research. In the past decade, enormous progress has been made in developing new fabrication techniques and materials for developing small devices. One of the most promising applications of miniaturization technology is in the biomedical industry. The biomedical industry, today, is characterized by irreconcilable demands: 1) patients are seeking better care; while 2) healthcare providers and insurance companies are calling for increasingly cost-effective diagnoses and treatments. The biomedical industry thus faces the challenge of developing devices and materials that offer benefits to both constituencies [2].

The discovery of carbon nanotubes (CNTs) has the potential of revolutionizing the biomedical research as they can show superior performance because of their impressive structural, mechanical, and electronic properties (will be discussed in detail in a separate section latter) such as small size and mass, high

Manuscript received August 25, 2004; revised November 25, 2004. Asterisk indicates corresponding author.

*N. Sinha is with the Department of Systems Design Engineering, University of Waterloo, Waterloo, ON N2L3G1, Canada (e-mail: nsinha@engmail.uwaterloo.ca).

J. T.-W. Yeow is with the Department of Systems Design Engineering, University of Waterloo, Waterloo, ON N2L3G1, Canada (e-mail: jyeow@engmail.uwaterloo.ca).

Digital Object Identifier 10.1109/TNB.2005.850478

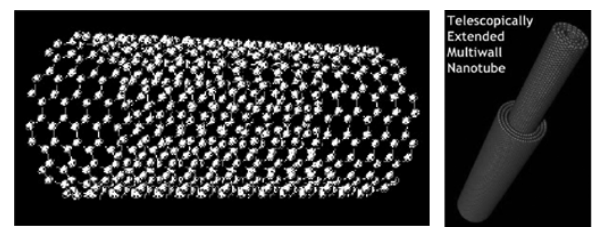

Fig. 1. (a) Structure of SWNTs. (b) Structure of MWNTs. Taken from [6], with permission.

strength, higher electrical and thermal conductivity, etc. [3], [4]. They are hexagonal networks of carbon atoms $\sim 1 \mathrm{~nm}$ in diameter and 1-100 $\mu \mathrm{m}$ in length and can essentially be thought of as a layer of graphite rolled up into a cylinder [5]. There are two types of nanotubes: single-walled nanotubes (SWNTs) and multiwalled nanotubes (MWNTs), which differ in the arrangement of their graphene cylinders. SWNTs have only one single layer of graphene cylinders; while MWNTs have many layers (approximately 50), as shown in Fig. 1 [6]. Furthermore, the films of synthesized CNTs can be aligned or random in nature [7]. Sketches of aligned and random CNTs are shown in Fig. 2.

Although CNTs look promising, they are also plagued with certain limitations, which prohibit their use on a large scale. The objectives of this paper are: 1) to describe the synthesis and purification techniques for CNTs; 2) to perform an extensive survey to investigate the areas in biomedical industry where CNTs can be potentially applied; 3 ) to outline the potential challenges it will face before gaining full industrial acceptance; and 4) to suggest possible research topics for solving problems using CNTs.

\section{Synthesis AND PURIFICATION TECHNIQUeS}

Generally, three techniques are being used for producing CNTs: 1) the carbon arc-discharge technique [3], [8]-[16]; 2) the laser-ablation technique [17]-[20]; and 3) the chemical vapor deposition (CVD) technique [21]-[31]. Among the CNTs, MWNTs were first discovered by Ijima in 1991 by the arc-discharge method [3]. After two years, Ijima and Ichihashi [10] and Bethune et al. [11] produced SWNTs. The SWNTs were produced using metal catalyst in the arc-discharge method. Thess et al. [17] synthesized bundles of aligned SWNTs by the laser-ablation technique. For the first time, catalytic growth of MWNTs by CVD was proposed by Yacaman et al. [21]. The three techniques are discussed in detail below.

\section{A. Carbon Arc-Discharge Technique}

The carbon arc-discharge technique utilizes two carbon electrodes to generate an arc by dc current. Fig. 3 shows the schematic diagram of the arc-discharge method. Initially, the two electrodes are kept independent. The electrodes are kept in a vacuum chamber and an inert gas is supplied to the chamber. 


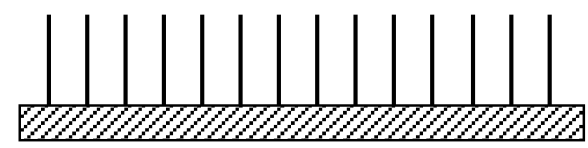

(a)

Fig. 2. (a) Aligned CNTs. (b) Random CNTs.

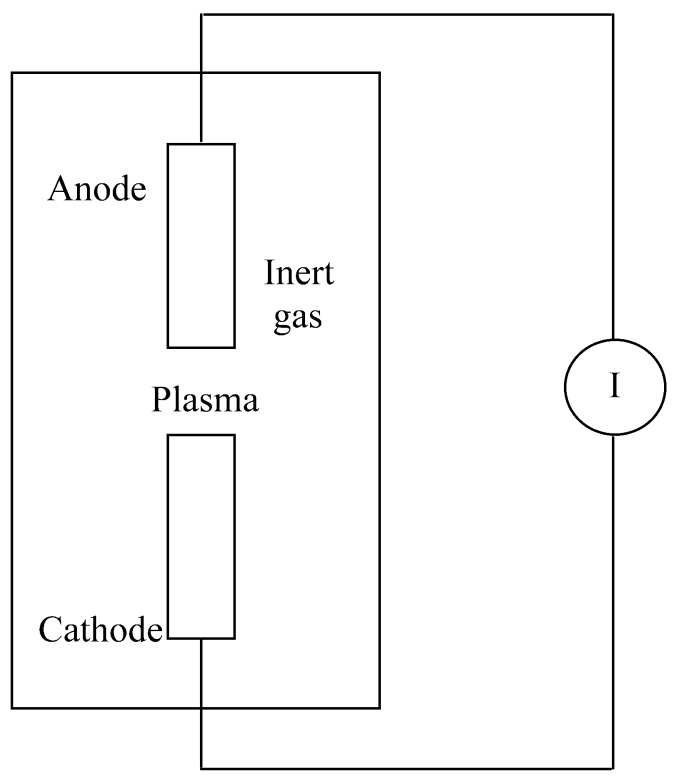

Fig. 3. Schematic diagram of carbon arc-discharge technique of producing CNTs.

The inert gas increases the speed of carbon deposition. Once the pressure is stabilized, the power supply is turned on (about $20 \mathrm{~V}$ ). The positive electrode is then gradually brought closer to the negative one to strike the electric arc. The electrodes become red hot and a plasma forms. Once the arc stabilizes, the rods are kept about a millimeter apart while the CNT deposits on the negative electrode. Once a specific length is reached, the power supply is cut off and the machine is left for cooling. The two most important parameters to be taken care of in this method are: 1) the control of arcing current and 2) the optimal selection of inert gas pressure in the chamber [32].

The arc-discharge technique produces high quality MWNTs and SWNTs. MWNTs do not need a catalyst for growth, while SWNTs can only be grown in the presence of a catalyst. MWNTs can be obtained by controlling the pressure of inert gas in the discharge chamber and the arcing current. In the case of MWNT growth by the arc-discharge method, the by-products are polyhedron-shaped multilayered graphitic particles. For the first time, Ebbesen and Ajayan [9] synthesized high-quality MWNTs having diameters in the range of 2-20 nm and lengths of several micrometers at the gram level. They applied a potential of $\sim 18 \mathrm{~V}$ and a helium pressure of $\sim 500$ torr. Analysis by transmission electron microscopy (TEM) revealed that the nanotubes consisted of two or more carbon shells. The MWNTs produced by the arc-discharge method were highly crystalline and were bound together by strong van der Waals forces. Ijima and Ichihashi [10] used a gas mixture of 10-torr methane and 40-torr argon at a dc current of $200 \mathrm{~A}$ and a voltage of $20 \mathrm{~V}$

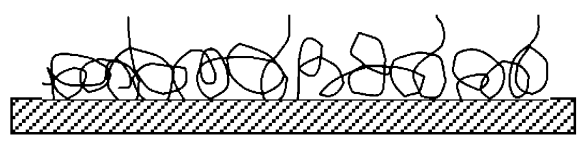

(b)

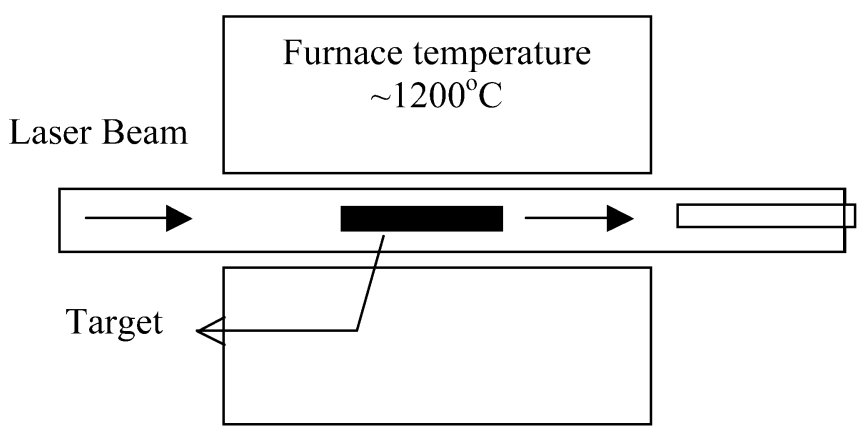

Fig. 4. Schematic diagram of laser-ablation technique of producing CNTs.

to synthesize SWNTs with diameters $\sim 1 \mathrm{~nm}$. Carbon anode and $\mathrm{Co}, \mathrm{Ni}$, and $\mathrm{Fe}$ as catalysts were tried by Bethune et al. [11]. They used a current of 95-105 A and a He pressure of 100-500 torr. The TEM analysis revealed that SWNTs were obtained only with Co catalysts, and the diameters of CNTs were $1.2 \pm 0.1 \mathrm{~nm}$. Journet et al. [16] optimized the SWNT growth by the arc-discharge method. They used a graphite cathode (16-mm diameter, $40 \mathrm{~mm}$ long), a graphite anode (6-mm diameter, $100 \mathrm{~mm}$ long), a mixture of catalyst ( $\mathrm{Ni}-\mathrm{Co}$, Co-Y, or Ni-Y), a helium pressure of 660 mbar, an arcing current of $100 \mathrm{~A}$, and a voltage drop of $30 \mathrm{~V}$ between the electrodes. Scanning electron microscopy (SEM) revealed that the deposited material consisted of high amount of entangled carbon ropes of diameters 5-20 nm. Li et al. [14] used the modified arc-discharge method, which used FeS as a promoter, to synthesize SWNTs. The diameters of CNTs were 5-20 $\mu \mathrm{m}$ and their length could reach $10 \mathrm{~cm}$. As evaluated by SEM, thermogravimetric analysis, and Raman spectroscopy, the synthesized SWNT fibers were $80 \%$ pure by volume.

\section{B. Laser-Ablation Technique}

In the laser-ablation technique used by Thess et al. [17] for producing CNTs, intense laser pulses were utilized to ablate a carbon target. The pulsed laser-ablation of graphite in the presence of an inert gas and catalyst formed SWNTs at $1200{ }^{\circ} \mathrm{C}$. Fig. 4 shows the schematic diagram of the laser-ablation technique. The X-ray diffraction (XRD) and TEM revealed that the SWNTs produced by laser-ablation were ropes (or bundles) of 5-20 nm diameter and tens to hundreds of micrometers of length. Braidy et al. [18] synthesized SWNTs and other nanotubular structures (graphite nanocages and low aspect ratio nanotubules) by pulsed $\mathrm{KrF}$ laser-ablation of a graphite pellet at an argon pressure of 500 torr, a temperature of $1150{ }^{\circ} \mathrm{C}$, and a laser intensity of $8 \times 10^{8} \mathrm{~W} / \mathrm{cm}^{2}$. They observed that relatively high UV laser intensity was detrimental to the growth of SWNTs. By using high vacuum laser-ablation, Takahashi et al. [19] synthesized multilayered MWNTs having a tip 


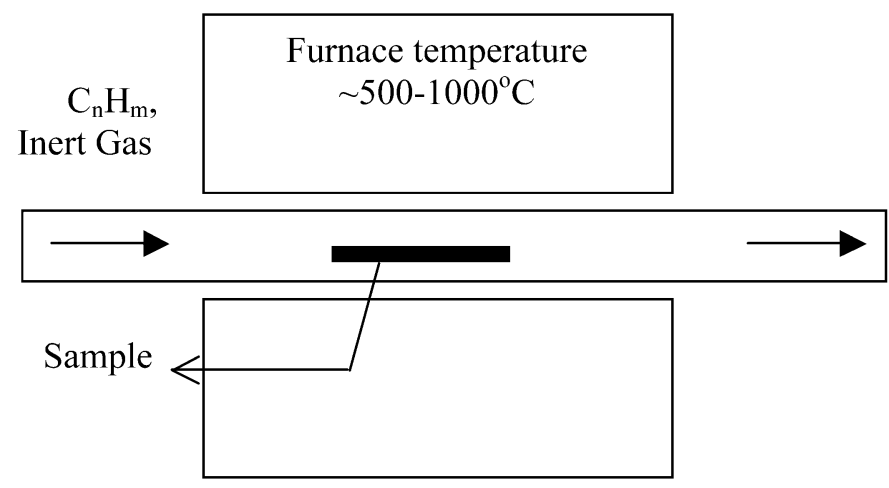

Fig. 5. Schematic diagram of CVD technique of producing CNTs.

angle of $15-20^{\circ}$. Graphite powder was dispersed on a $\mathrm{Si}(100)$ substrate and CNTs were grown selectively at high substrate temperature.

In general, some of the major parameters that determine the amount of CNTs produced are the amount and type of catalysts, laser power and wavelength, temperature, pressure, type of inert gas present, the fluid dynamics near the carbon target, etc. [33]. When synthesizing SWNTs, the by-products in the case of the arc-discharge and laser-ablation techniques are fullerenes, graphitic polyhedrons with enclosed metal particles, and amorphous carbon [33].

\section{CVD Technique}

In the CVD method, CNTs are synthesized by taking hydrocarbons (the commonly used sources are methane, ethylene, and acetylene) and using an energy source, such as electron beam or resistive heating, to impart energy to them. The energy source breaks the molecule into reactive radical species in the temperature range of $550-750{ }^{\circ} \mathrm{C}$. These reactive species then diffuse down to the substrate, which is heated and coated in a catalyst (usually a first-row transition metal such as $\mathrm{Ni}$, $\mathrm{Fe}$, or, $\mathrm{Co}$ ), where it remains bonded. As a result, the CNTs are formed. Fig. 5 shows the schematic diagram of the CVD technique. Yacman et al. [21] synthesized microtubules of up to $50 \mu \mathrm{m}$ length of CNTs by catalytic decomposition of acetylene over iron particles at $700^{\circ} \mathrm{C}$. Li et al. [22] used iron nanoparticles (embedded in mesoporous silica) as catalyst for large-scale synthesis of aligned CNTs. The tubes were $\sim 50 \mu \mathrm{m}$ long and well graphitized. Varadan and Xie [25] developed a CVD technique using microwave energy for synthesizing MWNTs. They used acetylene as the hydrocarbon and cobalt as the catalyst at a temperature of $700{ }^{\circ} \mathrm{C}$. MWNTs prepared by this process had an average diameter of 20-30 nm and consisted of 26 layers. Park et al. [27] utilized a sequential combination of radio frequency plasma-enhanced CVD (RF PECVD) and thermal CVD to synthesize CNTs from acetylene and hydrogen gas mixture on stainless steel plates. Seidel et al. [30] synthesized dense networks of SWNTs using Ni catalyst layers of $0.2 \mathrm{~nm}$ thickness by thermal CVD at temperatures as low as $600{ }^{\circ} \mathrm{C}$. They proposed a growth model for CVD synthesis on the basis of their experimental observations that was based on the interaction between the catalyst and its support. According to them, the fast growth rates of SWNTs during CVD synthesis can only be explained by surface diffusion of hydrocarbons on the catalyst support or along the CNTs. For the first time, metal (Fe)-encapsulated dendrimers were used as catalysts for low- temperature growth of CNTs by Vohs et al. [31]. MWNTs were synthesized at $175^{\circ} \mathrm{C}$ via decomposition of carbon tetrachloride in supercritical carbon dioxide by them.

There are several parameters which affect the synthesis of CNTs by the CVD technique. The key parameters are the nature of hydrocarbons, catalysts, and the growth temperature. For synthesizing MWNTs, most of the CVD techniques utilize ethylene or acetylene as hydrocarbons. Chaisitsak et al. [28] observed that both SWNTs and MWNTs can be synthesized by optimizing the catalyst. By optimizing the growth conditions, SWNTs of diameter $0.65 \mathrm{~nm}$ were synthesized by them at a substrate temperature of $660{ }^{\circ} \mathrm{C}$. With regards to the effect of temperature, the density and growth rate of CNTs increase with an increase in temperature. Also, as the temperature increases, the CNTs tend to be vertically aligned. By using CVD, excellent alignment and positional control on the nanometer scale can be achieved in addition to controlling the diameter and the growth rate. A major drawback with the CVD technique is that there are high defect densities in the MWNT structures grown by this process. It is believed that it is most likely due to the lack of sufficient thermal energy for annealing CNTs because of relatively low growth temperature [33].

A comparison among these three CNT synthesis techniques indicates that arc-discharge and laser-ablation methods have high yields ( $>70 \%$ ) of SWNTs. Between these two techniques, the cost of producing CNTs by the arc-discharge method is less compared to the laser-ablation method. However, the main disadvantages with these processes are: 1) tangled CNTs are synthesized by these processes that make the purification and applications of CNT samples difficult and 2) these processes rely on evaporation of carbon atoms at temperatures $>3000^{\circ} \mathrm{C}$ [34]. Apart from materials scale-up, controlled synthesis of aligned and ordered CNTs can be achieved by using CVD [35]. The microstructure of the CNT tips synthesized by the CVD technique have well-formed caps compared to other techniques. The shapes of tips are more rounded and have higher radius compared to arc-discharge tube tips. However, they often have interrupted graphite layers. In applications such as scanning probe microscopies, tips are very important. Although CVD process appears technologically easier, the required quality of tips can be made by the arc-discharge method [36].

\section{Purification}

In all the above-mentioned preparation methods, the nanotubes come with a number of impurities whose type and amount depend on the technique used. The most common impurities are carbonaceous materials, whereas metals are the other types of impurities generally observed [32]. In the carbon arc-discharge method, the impurities can be purified by oxidation as the carbonaceous impurities have high oxidation rates. However, in this case, $95 \%$ of the starting materials are destroyed and the remaining samples require annealing at high temperature $\left(\sim 2800^{\circ} \mathrm{C}\right)$ [37]. For purification by oxidation, generally two approaches are followed: 1) gas phase purification [37], [38] and 2) liquid phase purification [39]-[41]. 
Ebbesen et al. [37] observed low yield of purification by gas phase oxidation. Therefore, liquid phase oxidation was tried by Hiura et al. [39] for more homogeneous oxidation. Kim et al. [41] used nitric acid, sulphuric acid, and their mixture as oxidants. As observed by SEM, purified SWNTs of length less than $2 \mu \mathrm{m}$ were obtained. TEM confirmed that the SWNTs were purified with little damage on the surface and metal catalysts were efficiently removed. They characterized the size distribution with the field-flow fractionation (FFF) method. A purification technique for SWNTs that are synthesized by the pulsed laser-ablation technique was proposed by Bandow et al. [42]. They used a cationic surfactant and trapped SWNTs on a membrane filter. They observed $90 \%$ purity by weight after purification. For the SWNTs grown by CVD of carbon monoxide, a purification process has been developed by $\mathrm{Xu}$ et al. [43]. The purification process included sonication, oxidation, and acid washing steps. After purification, the purity and yield were determined and estimated by them using TEM. MWNTs grown by the CVD technique were subjected to wet and dry oxidation by Biro et al. [44] to remove impurities and traces of catalysts. It was observed that the $\mathrm{KMnO}_{4} / \mathrm{H}_{2} \mathrm{SO}_{4}$ aqueous oxidation procedure was effective in reducing the Co catalyst while moderately damaging the outer wall of CNTs.

Some other techniques have also been used to purify CNTs. Shelimov et al. [45] used ultrasonically assisted microfiltration for purifying SWNTs from amorphous and crystalline carbon impurities and metal particles. SWNTs with more than $90 \%$ purity were generated by this process. Dujardin et al. [46] boiled CNTs in nitric acid aqueous solutions to remove amorphous carbon and metal particles. Harutyunyan et al. [47] developed a scalable purification method for SWNTs by using microwave heating in air followed by treatment with hydrochloric acid. Ko et al. [48] have developed a purification technique for MWNTs using microwave-assisted purification. They found by Raman spectroscopy and thermogravimetric analysis that a temperature of $180^{\circ} \mathrm{C}$ was suitable for the purification of CNTs. They observed that purification temperatures above $180^{\circ} \mathrm{C}$ decomposed the nanotubes, while temperatures below $180^{\circ} \mathrm{C}$ were not effective in removing defects.

As a concluding remark, the above-mentioned purification methods change the structural surfaces of CNTs. As a result, there may be change in the electrical and mechanical properties of purified nanotubes. Therefore, the main thrust of the research should be in the area of producing purified CNTs in a single-step process to conserve the fascinating features of CNTs.

\section{PROPERTIES OF CNTS}

Before exploring the potential applications of CNTs, an overview of their properties is very important because the applications of CNTs are related to some of their specific properties. For example, CNTs can be used as hydrogen storage media because they have the ability to elastically sustain loads at large deflection angles. It enables them to store or absorb considerable energy [49]. Although SWNTs are structurally similar to a single layer of graphite (that is, a semiconductor with zero band gap), they can be either metallic or semiconducting depending upon the tube diameter and the chirality (the
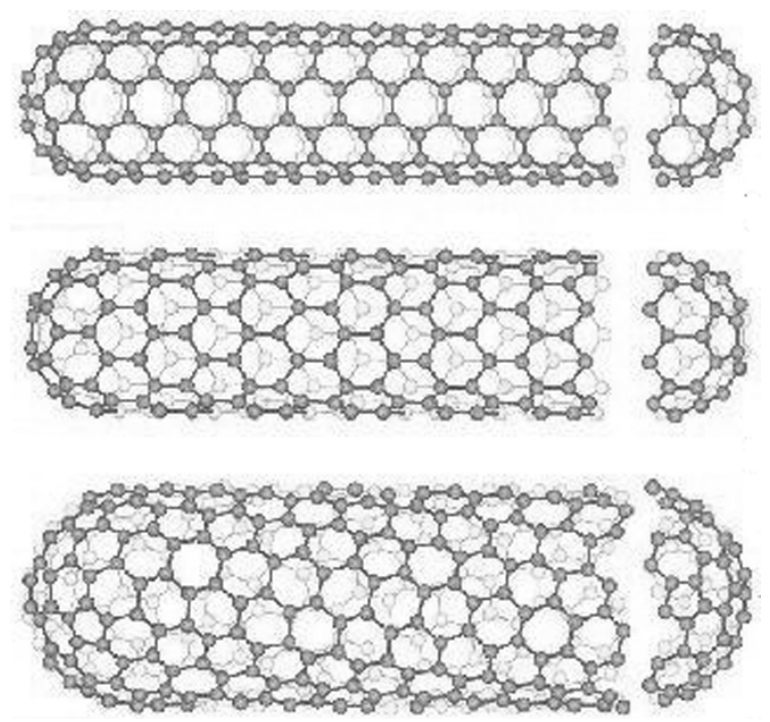

Fig. 6. (a) Armchair, (b) zigzag, and (c) chiral nanotubes. Taken from [5], with permission.

sheet direction in which the graphite sheet (so-called graphene) is rolled to form a nanotube cylinder [50], [51]). The direction and diameter can be obtained by an integer pair $(n, m)$ using (1) and (2) [52].

$$
\begin{aligned}
& d=\frac{a \sqrt{m^{2}+m n+n^{2}}}{\pi} \\
& \theta=\arctan \left[-\frac{\sqrt{3} n}{2 m+n}\right]
\end{aligned}
$$

where $a$ is the lattice constant in the graphite sheet and $\theta$ is the chiral angle.

The relation between $n$ and $m$ defines three categories of CNTs: 1) armchair ( $n=m$ and chiral angle equal to $\left.30^{\circ}\right)$; 2) zigzag $\left(n=0\right.$ or $m=0$ and chiral angle $\left.=0^{\circ}\right)$; and 3) chiral (other values of $n$ and $m$ and chiral angles between $0^{\circ}$ and $30^{\circ}$ ) [53]. Fig. 6 shows all the three categories of CNTs [5]. All armchair SWNTs are metals, while those with $n-m=3 j$ ( $j$ being a nonzero integer) are semiconductors with a tiny bandgap. All others are semiconductors, which have the bandgap that is inversely related to the diameters of the nanotubes [54]. MWNTs are either nested CNT shells [55] or have cinnamon-roll-like structure [56].

The dielectric responses of the CNTs are found to be highly anisotropic. The electronic transport in metallic SWNTs and MWNTs occurs ballistically (without scattering) over long lengths owing to the nearly one-dimensional electronic structure. This enables nanotubes to carry high currents with negligible heating [57]. Distortions like bending and twisting affect the electrical and electronic properties of nanotubes. Bending introduces pentagon-heptagon pair in CNTs; this results in metal-metal and semiconductor-metal nanoscale junctions that can be used for nanoswitches [58], [59]. The effect of bending becomes important when bending angles are more than $45^{\circ}$. At this stage, kinks appear in the structure of the tube. The ultimate effect of bending is reduction in conductivity of CNTs [60]. Upon twisting, a bandgap opens up that turns 
metallic CNTs to semiconducting CNTs. Twisting above a certain angle results in collapse of CNT structures [61]. Also, superconductivity in SWNTs has been observed, but only at low temperatures [62].

Mechanically, CNTs are currently the strongest known fibers. Determination of their strength and toughness is very important for applications. They are quite stiff and exceptionally strong because the carbon-carbon bond observed in graphite is one of the strongest in nature. Elastic properties of CNTs can be obtained from experiment by assuming them structural members. Treacy et al. [63] were the first to determine the Young's modulus (a measure of stiffness) of individual MWNTs. They estimated the Young's modulus of isolated CNTs by measuring the amplitude of their intrinsic thermal vibrations in the TEM. They observed the average value of Young's modulus as $1800 \mathrm{GPa}$. However, their technique has some limitations such as: 1) for reliable TEM detection, the thermally excited vibrations must be neither too large nor too small resulting in the restriction of the diameter and length of CNT samples and 2) strength (the maximum force per unit area) and toughness (the elastic energy stored or absorbed by a material) of CNTs cannot be determined by this technique [49]. Wong et al. [49] determined the mechanical properties of MWNTs using atomic force microscopy (AFM) by pinning them at one end to molybdenum disulfide surfaces. They observed the average value of Young's modulus as $1280 \mathrm{GPa}$. Falvo et al. [64] used the tip of an atomic force microscope to observe that MWNTs can be bent repeatedly through large angles without undergoing catastrophic failures. All these studies suggest that multilayered CNTs are very strong in nature and are remarkably flexible and resistant to fracture when subjected to large strain. Recently, more studies for determining the elastic properties have been reported. However, a comparison of these studies indicates that the values of the mechanical parameters are quite confusing. For instance, a study by Lourie and Wagner [65] reported the Young's modulus of SWNTs as 2800-3600 GPa and that of MWNTs as 1700-2400 GPa. On the other hand, Yu et al. [66], [67] reported the Young's modulus of SWNTs between 320 and $1470 \mathrm{GPa}$ and that of MWNTs between 270 and $950 \mathrm{GPa}$. This is because some researchers use the total occupied cross-sectional area for defining the Young's modulus, while others use the much smaller van der Waals area [51]. Materials made of nanotubes are lighter and more durable because they have low density $\left(1.3 \mathrm{~g} / \mathrm{cm}^{3}\right)$. As they have very small diameters and large length, they have very high aspect ratio. As a result, CNT structures are susceptible to structural instability. However, SWNTs have better defined shapes of cylinders than MWNTs. Therefore, MWNTs have more possibilities of structure defects and their nanostructure is less stable. As a result, SWNT is preferred over MWNT for carrying out research and for developing applications [6].

It is extremely challenging to measure the tensile strength of CNTs. Yu et al. [66], [67] performed tensile load testing and found it to be in the range of 13-52 GPa for SWNT bundles while the value was 11-63 GPa for MWNTs. In the case of MWNTs, it was observed that only the outermost layer breaks during the tensile load testing process. Wong et al. [49] measured the bending strength of large-diameter MWNTs. Ac- cording to them, bending strength is the strain determined at the initial buckling point because the stiffness drops significantly at this point. The average value of bending strength determined by them was $14.2 \pm 8.0 \mathrm{GPa}$, while the maximum value was $28.5 \mathrm{GPa}$. Compressive loading of MWNTs resulted in the compressive strength of 100-150 GPa and compressive strain of 5\% [68]. Also, it was found that the fracture strength and the elastic limit of nanotubes depend on their chirality [69], [70].

It was observed that temperature plays a key role in the strength of CNTs. This is because motion of dislocations is thermally activated. At low temperature, CNTs are brittle in nature, irrespective of their diameter and helicity. However, CNTs exhibit flexibility at room temperature due to their high strength and the distortion capability of hexagonal network for relaxing stress [71]. At high temperature, spontaneous formation of double pentagon-heptagon (or 5/7) pairs were observed in strained CNTs. It was found that such defects depend on the chirality of CNTs and are energetically favored in defect-free armchair nanotubes when the tensile strain is greater than $5 \%$. These defects constitute the onset of the possible plastic deformation of CNTs [72]. It is important to mention here that the high strength and high stiffness properties of an individual SWNT does not necessarily imply that CNT structures will have the same properties [55].

CNTs show good load transfer characteristics with metal matrix composites. Efficient load transfer between a matrix and CNTs plays a key role in the mechanical properties of composites and can lead to development of many superstrong nanocomposites. However, poor load transfer behavior of CNTs in tension compared to compression was observed because only the outermost nanotubes is loaded in tension due to weak interlayer bonding [71].

The specific heat and thermal conductivity of CNTs are dominated by phonons, as the electronic contribution is negligible due to low density of free charge carriers [73]. Experiments were performed by Yi et al. [74] for measurements of specific heat of MWNTs. The measurements revealed linear dependence of the specific heat on the temperature over the entire temperature interval. MWNTs and bundles of SWNTs with average diameter of $1.3 \mathrm{~nm}$ were used by Mizel et al. [75] to measure the specific heat in the temperature range $1<\mathrm{T}<200 \mathrm{~K}$. While MWNTs exhibited graphite-like behavior, SWNT bundles had steep temperature dependence at low temperatures. The specific heat of SWNT bundles was measured by Lasjaunias et al. [76] down to a temperature of $0.1 \mathrm{~K}$. The presence of sublinear temperature dependence of specific heat, dominant below $\sim 1 \mathrm{~K}$, was observed. This dependence could not be understood and warrants further investigation into the thermal properties of CNTs. For measuring thermal conductivities of CNTs to isotopic and other atomic defects, the domination of phonons leads to unusual sensitivity of the experiments [77]. Zhang et al. [78] found that the thermal conductivity of SWNTs depends on their length, radius, temperature, and chirality. Therefore, nanoscale devices with different heat conductivities can be made with nanotubes of different chirality. They also observed that the value of heat conductivity of zigzag nanotube is maximum, while the chiral nanotube has a minimum value. Kim et al. [79] determined that at room temperature, the thermal conductivity for an indi- 


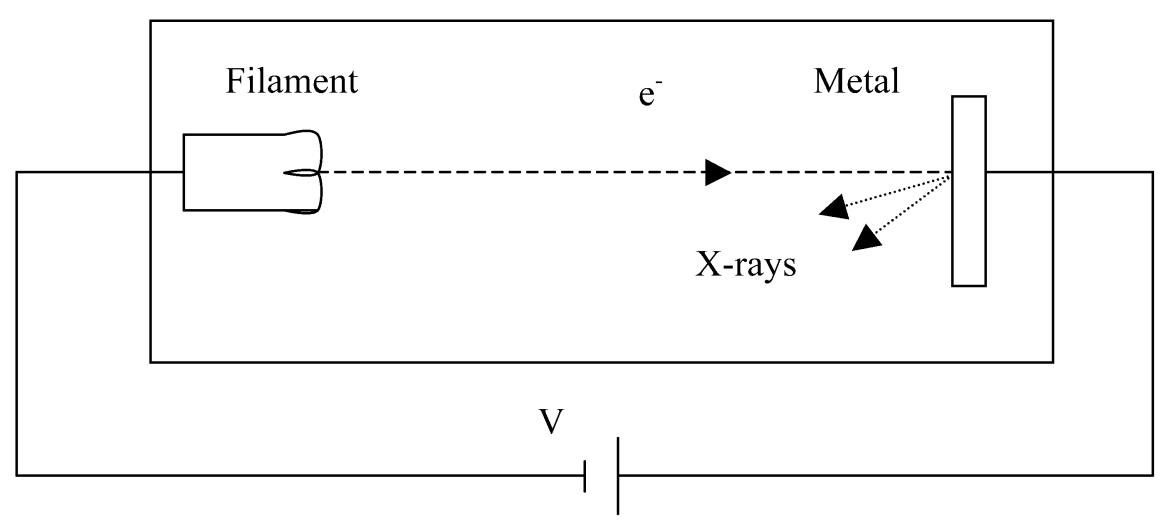

Fig. 7. Traditional method of generating x-rays.

vidual MWNT ( $>3000 \mathrm{~W} / \mathrm{mK}$ ) is greater than that of graphite $(2000 \mathrm{~W} / \mathrm{mK})$.

Properties of CNTs were briefly reviewed in this section. Even though the properties of CNTs have been studied extensively in recent years, only the tip of the iceberg has been addressed. A database of properties of CNTs as a function of concentration and type of defects, chemical environment, temperature, chemical environment, and so on should be established to reap their benefits.

\section{ApPlications}

In the last few years, several studies have been proposed indicating potential applications of CNTs [4], [34], [51], [52], [80], [81]. The applications include the use of CNTs in energy storage and energy conversion devices [82]-[87], high-strength composites [88]-[94], nanoprobes and sensors [95]-[116], actuators [117]-[124], electronic devices [7], [125]-[134], production of nanorods using CNTs as reacting templates [135]-[138], catalysis [139]-[144], and hydrogen storage media [145]-[151]. However, this paper attempts to report the existing and future applications of CNTs in the biomedical industry exclusively. The following sections detail the areas in biomedical engineering where CNTs can be potentially applied.

\section{A. Diagnostic Tools and Devices}

1) Radiation Oncology: The traditional method of generating $\mathrm{x}$-rays comprises of a metallic filament (cathode) that acts as a source of electron when it is heated resistively to a very high temperature. The accelerated electrons (that are emitted) are bombarded on a metal target (anode) to generate x-rays, as shown in Fig. 7. The advantage associated with this method is that it works even in nonultrahigh vacuum ambiences, which contain various gaseous molecules. This method has several limitations: 1) it has slow response time; 2) consumes high energy; and 3) has limited lifetime. Recent research has reported that field emission is a better mechanism of extracting electrons compared to thermoionic emission [152]. This is because electrons are emitted at room temperature and the output current is voltage controllable. In addition, giving the cathode the form of tips increases the local field at the tips and, as a result, the voltage necessary for electron emission is lowered [153]. An optimal cathode material should have high melting point, low work function, and high thermal conductivity. CNTs can be used as a

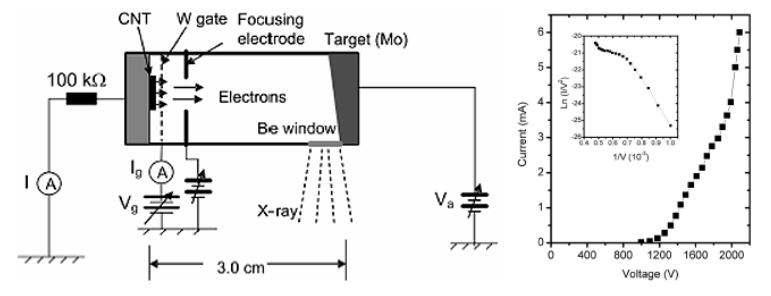

Fig. 8. (a) Schematic drawing of the CNT-based microfocus x-ray tube. (b) Electron emission current versus applied voltage obtained from a 1-mm² CNT cathode. Taken from [157], with permission.

cathode material for generating free flowing electrons. Electrons are readily emitted from their tips either due to oxidized tips or because of curvature when a potential is applied between a CNT surface and an anode [154]-[156]. Yue et al. [152] generated continuous and pulsed x-rays using a CNT-based field emission cathode. The field emission currents were found to follow the Fowler-Nordheim relation

$$
I=a V^{2} \exp \left(-\frac{b}{V}\right)
$$

where $V$ is the applied voltage and $a$ and $b$ are constants that are dependent on the cathode geometry and work function. Plotting $1 / V$ against $\ln \left(I / V^{2}\right)$ yields a straight line for a current of field emission origin. Yue et al. [152] could obtain a total emission current of $28 \mathrm{~mA}$ from a $0.2-\mathrm{cm}^{2}$-area CNT cathode. By programming the gate voltage, pulsed $\mathrm{x}$-ray with a repetition rate greater than $100 \mathrm{kHz}$ was readily achieved. The $\mathrm{x}$-ray intensity was sufficient to image human organs at $14 \mathrm{kVp}$ and $180 \mathrm{mAs}$. Recently, a dynamic radiography system using CNT-based field emission has been proposed by Cheng et al. [157]. The schematic of the CNT-based microfocus x-ray tube is shown in Fig. 8(a). X-ray radiation with continuous variation of temporal resolution as short as nanoseconds can be readily generated by their system. The diameter of cathode used by them was $1 \mathrm{~mm}$ with randomly oriented CNTs. Under pulsed mode, they observed a peak emission current up to $6 \mathrm{~mA}$ at a gate electric field of $\sim 15 \mathrm{~V} / \mu \mathrm{m}\left(V_{g}=2060 \mathrm{~V}\right)$; see Fig. 8(b).

The advantages of CNT-based $\mathrm{x}$-ray devices are fast response time, fine focal spot, low power consumption, possible miniaturization, longer life, and low cost. Besides, it minimizes the need of cooling required by the conventional method [152], [158], [159]. Miniaturized x-ray devices can be inserted into the body by endoscopy to deliver precise $\mathrm{x}$-ray doses directly 
at a target area without damaging the surrounding healthy tissues, as malignant tumors are highly localized during the early stage of their development. With time, the cancer spreads to neighboring anatomic structures. Other processes such as chemotherapy and conventional radiation doses kill the cancer but may also kill healthy tissues. This is not desired from a health point of view.

2) Sensors: Sensors are devices that detect a change in physical quantity or event. There are many studies that have reported use of CNTs as pressure, flow, thermal, gas, and chemical and biological sensors, as mentioned at the beginning of this section. Liu and Dai [99] demonstrated that piezoresistive pressure sensors can be made with the help of CNTs. They grew SWNTs on suspended square polysilicon membranes. When uniform pressure was applied on the membranes, a change in resistance in the SWNTs was observed. According to Caldwell et al. [100], silicon piezoresistors have the disadvantage that their resistance is highly sensitive to variations in temperature. As CNTs have temperature coefficient almost two orders of magnitude lower than that of silicon and have increased sensitivity, highly efficient pressure sensors incorporating CNTs can be fabricated. Fabrication of piezoresistive pressure sensors that incorporate CNTs can bring dramatic changes in the biomedical industry, as many piezoresistance-based diagnostic and therapeutic devices are currently in use there. Pressure sensors can be used in eye surgery, hospital beds, respiratory devices, patient monitors, inhalers, and kidney dialysis machines [2], [160]. During eye surgery, fluid is removed from the eye and, if required, cleaned and replaced. Pressure sensors measure and control the vacuum that is used to remove the fluid, and provide input to the pump's electronics by measuring barometric pressure. Hospital bed mattresses for burn victims consist of pressure sensors that regulate a series of inflatable chambers. To reduce pain and promote healing, sections can be deflated under burn areas. Pressure sensors can also be used for sleep apnea (a cessation of breathing during sleep) detection. The pressure sensor monitors the changes in pressure in inflated mattresses. If no movement is found for a certain period, the sleeper is awakened by an alarm [160]. Pressure sensing technology is used in both invasive and noninvasive blood pressure monitors. Many patients who use inhalers activate their inhalers at an inappropriate time, resulting in an insufficient dose of medication. Pressure sensors in the inhalers identify the breathing cycle and release the medication accordingly [2]. During kidney dialysis, blood flows from the artery to the dialysis machine and after cleaning flows back into the vein. Waste products are removed from the blood through osmosis and move across a thin membrane into a solution that has blood's mineral makeup [161]. Using pressure sensors, the operation of the dialysis system can be regulated by measuring the inlet and outlet pressures of both the blood and the solution. Intelligent pressure sensing systems play an important role in portable respiratory devices that consist of both diagnostic (spirometers, ergometers, and plethysmographs) and therapeutic (ventilators, humidifiers, nebulizers and oxygen therapy equipment) equipments. They serve patients with disorders of asthma, sleep apnea, and chronic obstructive pulmonary disease. They measure pressure by known fluid dynamic principles [2].

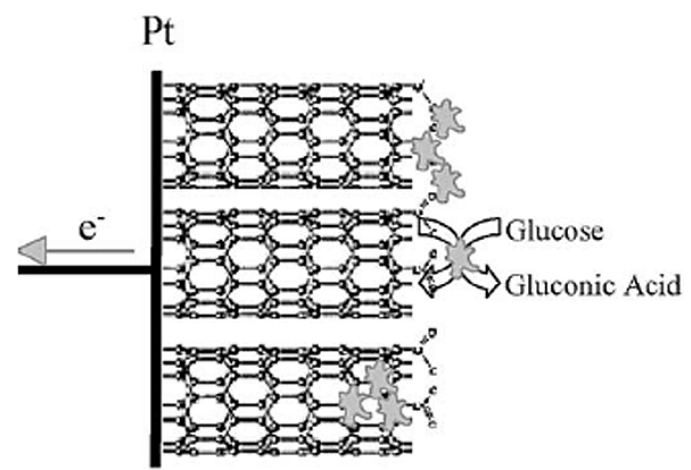

Fig. 9. Schematic diagram of the CNT array biosensor. Taken from [106], with permission.

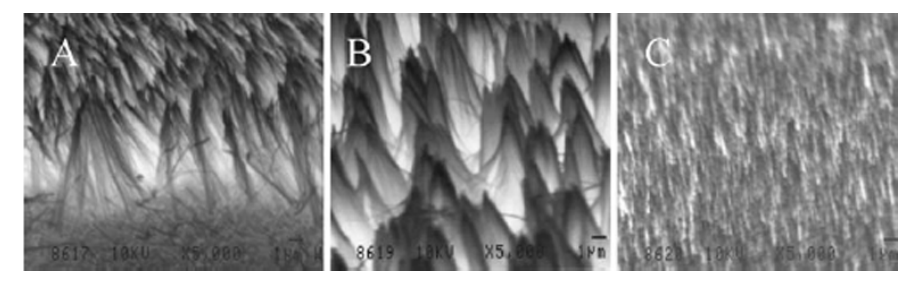

Fig. 10. SEM images of Pt-aligned CNT arrays. (a) In original state. (b) After acid treatment. (c) After air oxidation. Taken from [106], with permission.

Sotiropoulou and Chaniotakis [106] used CNTs as immobilization matrix for the development of an amperometric biosensor. The biosensor was developed by growing aligned MWNTs on platinum (Pt) substrates. The platinum substrate served as the transduction platform for signal monitoring, whereas opening and functionalization of large CNT arrays allowed for the efficient immobilization of the model enzyme (glucose oxidase in this case). The schematic diagram of the CNT array biosensor is shown in Fig. 9. The arrays were purified by treatments with acid or air. The acid treatment resulted in the removal of impurities including amorphous carbon that occurred during the production procedure. The lengths of the nanotubes were also reduced by approximately $50 \%$. Air oxidation resulted in production of thinner nanotubes because of the peeling of the outer graphitic layers from the nanotubes. SEM images of the Pt-aligned CNT arrays are shown in Fig. 10.

CNT-based nanobiosensors may be used to detect DNA sequences in the body [162], [163]. These instruments detect a very specific piece of DNA that may be related to a particular disease [164]. Such sensors enable detection of only a few DNA molecules that contain specific sequences and thus possibly diagnose patients as having specific sequences related to a cancer gene. The use of nanotube-based sensors will avoid problems associated with the current much-larger implantable sensors, which can cause inflammation, and can eliminate the need to draw and test blood samples. The devices can be administered transdermally, or through the skin, avoiding the need for injections during space missions [165]. Biosensors can also be used for glucose sensing. CNT chemical sensors for liquids can be used for blood analysis (for example, detecting sodium or finding $\mathrm{pH}$ value) [166].

CNTs can also be used as flow sensors [104], [105]. Ghosh et al. [104] found that the flow of a liquid on bundles of SWNTs 


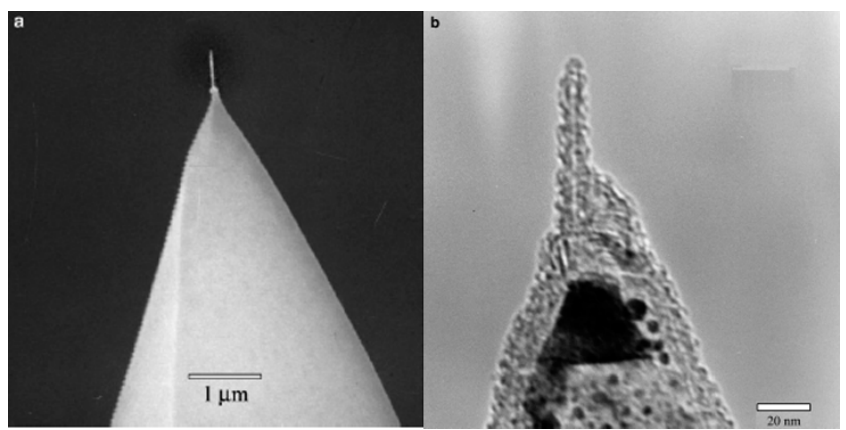

Fig. 11. Electron micrographs of two different AFM cantilever tips, each with a nanotube attached. (a) An SEM micrograph of a nanotube. (b) A TEM micrograph of a nanotube. Taken from [169], with permission.

induces a voltage in the direction of flow. In future, this finding can be used in micromachines that work in a fluid environment such as heart pacemakers that need neither heavy battery packs nor recharging. Flow sensors can also be used for precise measurements of gases utilized by respiratory apparatuses during surgery and automatic calculation of medical treatment fees based on output data leading to reduced hospital costs and more accurate calculation.

In summary, the advantages of CNT-based sensors are that they are less sensitive to variations in temperature (compared to silicon piezoresistors), which enables them perform better in many of the biomedical sensing applications mentioned above. Apart from it, their unique flow sensing properties can be exploited in making heart pacemakers. As CNT-based sensors are smaller in size, they consume less power, avoid chances of inflammation, and eliminate the need to draw and test blood samples. They can be used in detecting very specific pieces of DNA by utilizing their electron transfer characteristics and functionalization properties. This can help in detecting important cancerous genes and biomolecules such as antibodies associated with human autoimmune diseases.

3) Probes: Probes are devices that are designed to investigate and obtain information on a remote or unknown region or cavity. There are many studies that have reported the use of CNTs for making probes [167]-[173]. For example, Stevens et al. [169] attached AFM tips (the physical probe) using an arc-discharge method. The tips produced by them are shown in Fig. 11. They were able to image a protein filament using these tips.

CNTs are highly suitable materials for AFM probes, as the AFM-generated image is dependent upon the shape of the tip and surface structure of the sample of interest. An optimal probe should have vertical sides and a tip radius of atomic proportions. AFM tips made of silicon or silicon nitride are pyramidical in shape and have a radius of curvature around $5 \mathrm{~nm}$. Compared to them, nanoprobes made of CNTs have high resolution, as their cylindrical shape and small tube diameter enable imaging in narrow and deep cavities. In addition, probe tips made of CNTs have mechanical robustness and low buckling force. Low buckling force lessens the imaging force exerted on the sample and therefore can be applied for imaging soft materials such as biological samples. Besides, these factors enhance the life of probes and minimize sample damage during repeated hard crashes into substrates [51].

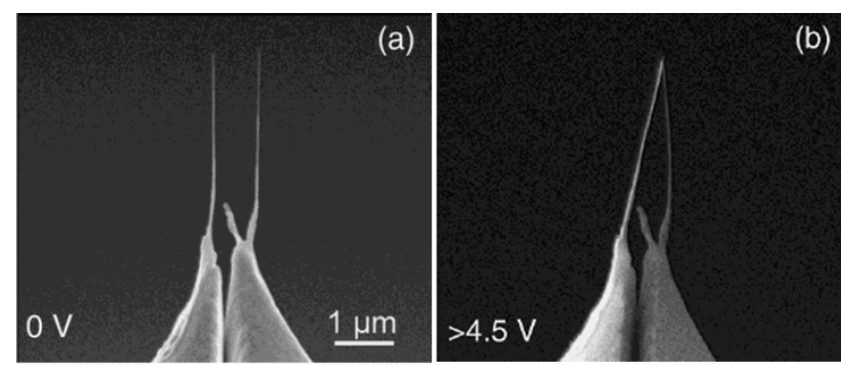

Fig. 12. SEM images of motion of typical nanotweezers. (a) Open. (b) Closed. Taken from [175], with permission.
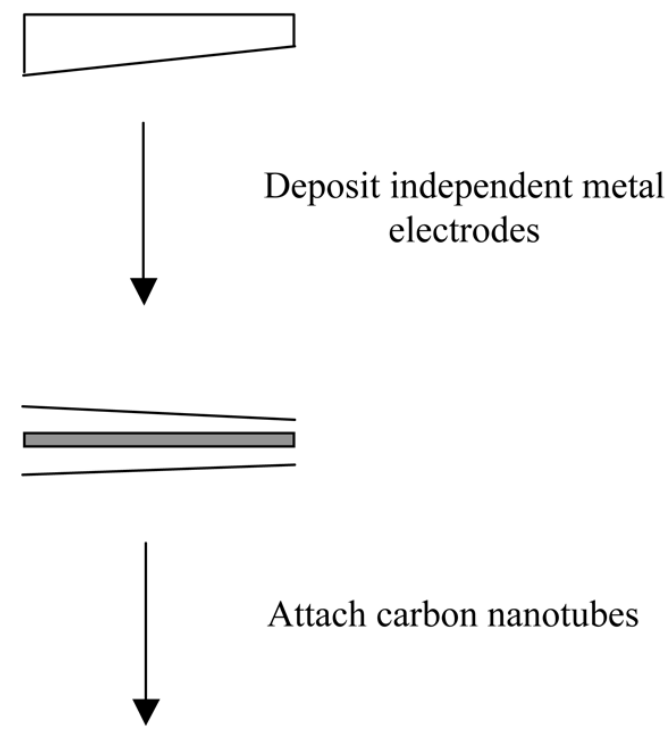

Attach carbon nanotubes

Fig. 13. Fabrication of nanotweezers. Taken from [176], with permission.

Nanotweezers are a type of probe that is driven by the electrostatic interaction between two nanotubes on a probe tip. Their operating principle is to balance the elastic restoring force with the electrostatic force [174]. An SEM image of a typical pair of prepared nanotube nanotweezers is shown in Fig. 12 [175]. To fabricate nanotweezers, a tapered glass micropipette is selected. Free standing electrically independent metal electrodes (generally of $\mathrm{Au}$ ) are deposited on the micropipettes. At the end, electrically controlled CNTs made from a bundle of MWNTs are attached to the independent electrodes. The fabrication process is shown in Fig. 13 [176].

Nanotube nanotweezers can be used for manipulation and modification of biological systems such as DNA and structures within a cell. Second, they can be used as nanoprobes for assembling structures. It will be helpful in increasing the value of measurement systems for characterization and manipulation at nanometer scale. Third, once a nanoscale object has been grasped by the nanotweezer, its electrical properties can be probed, as nanotube arms serve as conducting wires. Fourth, nanotweezers can be used as an electromechanical sensor for detection of pressure or viscosity of media by measuring the 

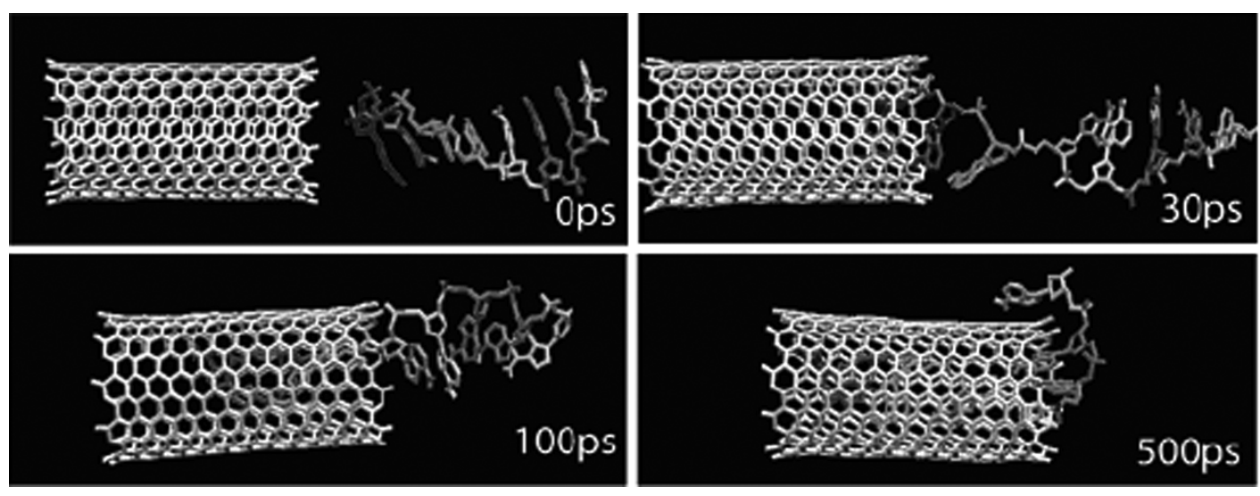

Fig. 14. Simulation snapshots of a DNA oligonucleotide interacting with a $(10,10)$ CNT at $0,100,30$, and 500 ps. Taken from [188], with permission.

change in resonance frequency [175], [176]. Using the developed nanotweezers, Kim and Lieber [176] were able to remove a semiconductor wire $20 \mathrm{~nm}$ wide from a mass of entangled wires. They were also able to grasp polystyrene spheres of 500-nm clusters. Currently, research is being carried to grow SWNTs onto the electrodes to produce nanotweezers to grab individual macromolecules [177].

Application of CNTs as nanoprobes for crossing the tumor but not crossing into healthy brain tissue should also be investigated, as the presence of cancer in a brain tumor may result in weakening of the blood-brain barrier.

4) Quantum Dots: Quantum dots are tiny light-emitting particles having length $\sim 2-10 \mathrm{~nm}$. They are a new class of biological labels. Semiconductor quantum dots can be used for quantitative imaging and spectroscopy of single cancer cells. They could possibly be applied for disease diagnostics, cancer imaging, molecular profiling, drug and biochemical discovery, disease staging, targeted therapeutics, and high-throughput drug screening. This is because of their dimensional similarity with biological molecules such as nucleic acids and proteins, and their size-tunable properties. In addition, they allow longer periods of observation and do not fade when exposed to UV light. They can also be used tracking many biological molecules simultaneously, as their color can be tailored by changing the size of the dot.

Researchers have shown that CNTs can form quantum dots. Tans et al. [178] and Bockrath et al. [179] were the first to observe the SWNT quantum dots during their experiments. Coulomb blockade and a quantization of electron states were shown by their transport experiment that implied that a CNT quantum dot had been formed. Buitelaar et al. [180] showed that MWNTs can also form clean quantum dots where the level separation exceeds the charging energy. Recently, a structure has been proposed to fabricate a quantum well on the order of a few nanometers by using the electromechanical properties of SWNTs [181]. When embedded in biological fluids and tissues, quantum dot excitation wavelengths are often quite constrained. Therefore, excitation and emission wavelengths should be selected carefully based on the particular application [182].

\section{B. Biopharmaceutics}

1) Drug Delivery: Like other device industries, increasing concerns over rising health care costs have led to the devel- opment of novel drug delivery techniques that are cost effective. The important characteristics of an efficient drug delivery system are the ability to perform controlled and targeted drug delivery [183]. For this purpose, drugs should be released at an appropriate rate, as rapid release of drugs may lead to incomplete absorption, gastrointestinal disorders, and other side effects. In addition, care needs to be taken so that the drugs will not decompose during delivery, as some drugs are toxic in nature. To this end, drugs should be encapsulated in a carrier during transit in the body while maintaining their biological and chemical properties [184]. Also, the drug delivery material must be compatible with the drug and should bind easily with it. The material should decompose at the completion of its use either by solubilizing or by elimination via excretory roots of the body.

CNTs can be used as a carrier for drug delivery, as they are adept at entering the nuclei of cells. Researchers have found that functionalized CNTs can cross the cell membrane [185], [186]. Besides, they are of a size where cells do not recognize them as harmful intruders [187]. Martin and Kohli [185] reported that CNTs can be used as drug delivery materials because they have larger inner volumes as compared to the dimensions of the tube that can be filled with desired chemical and biological species. Second, CNTs have distinct inner and outer surfaces that can be differentially modified for functionalization. As a result, the outer surface of CNTs can be immobilized with biocompatible materials and inside can be filled with the desired biochemical payload [140]. Third, CNTs have open mouths, which make the inner surface accessible for insertion of species inside the tube [188]. Molecular dynamics simulations show that van der Waals and hydrophobic forces are important for the insertion process. The van der Waals forces have a dominant role in the CNT species. Gao et al. [188] found that in a water solute environment, DNA molecule could be inserted into CNTs via an extremely rapid dynamic interaction process. The simulation snapshots are shown in Fig. 14. Based on their studies, they suggested that the encapsulated CNT-DNA molecular complex can be applied in DNA-modulated molecular electronics, molecular sensors, electronic DNA sequencing, and gene delivery systems. Kong et al. [189] found that the encapsulation of biological molecules in CNTs can be accelerated at high temperatures. Finally, CNTs can be organically functionalized to make them soluble in organic solvents and aqueous solutions. Soluble CNTs can be coupled with amino acids and bioactive peptides for further derivatization [186]. These drug delivery systems may form 
the basis for anticancer treatments, gene therapies, and vaccines in future, as the carrier can enter damaged cells and release enzymes either to initiate an autodestruct sequence of cells or to repair the cell for normal functioning. In the future, the application of CNTs as drug encapsulators for treatment of brain tumors can be investigated by determining if the drug crosses the blood-brain barrier or not. Other applications to be investigated include the use of CNTs to deliver drugs to the eye beyond the blood-retina barrier and to the central nervous system beyond the blood-brain barrier. If this finding is found successful, CNTs can be used for treating eye diseases and other diseases such as Alzheimer's and Parkinson's.

Another interesting area invokes using CNTs as pills that contain a miniaturized video system. The swallowed pill can be used for assessing diseases in areas that are difficult to access with other techniques such as endoscopies and colonoscopies [184].

2) Drug Discovery: Traditional trial-and-error methods have very high lead time that takes several years for a new drug to reach the market [184]. The critical bottlenecks in drug discovery may be overcome by using arrays of CNT sensors and current information technology solutions (such as data mining and computer-aided drug design) for identification of genes and genetic materials for drug discovery and development [190].

\section{Implantable Materials and Devices}

1) Implantable Nanosensors and Nanorobots: There are certain cases, such as diabetes, where regular tests by patients themselves are required to measure and control the sugar level in the body. Children and elderly patients may not be able to perform this test properly. Another similar example is regular tests of persons exposed to hazardous radiations or chemicals. The objective is the detection of the disease in its early stage so that appropriate action for higher chances of success can be taken. Implantable sensors and nanorobots can be useful in health assessment [191]. CNT-based nanosensors have the advantages that they are a thousand times smaller than even microelectromechanical systems (MEMS) sensors and consume less power. Therefore, because of their small size and less power consumption, they are highly suitable as implantable sensors. Implanted sensors can be used for monitoring pulse, temperature and blood glucose, and diagnosing diseases [192], [194]. Besides, CNTs can be used for repairing damaged cells or killing them by targeting tumors by chemical reactions. Implantable nanosensors can also monitor heart's activity level and regulate heartbeats by working with an implantable defribulator [184]. Possible application of CNTs for treatment of retinal diseases caused due to loss of photoreceptors can be investigated. One way of compensating the loss of photoreceptors is by bypassing the destroyed photoreceptors and artificially stimulating the intact cells in the neighborhood. Another possible area related to the application of CNTs that can be investigated is cochlear implants related to hearing problems.

According to Bhargava [191], implanted nanorobots can have following possible applications.
1) To cure skin diseases. A cream-containing nanorobot could remove the right amount of dead skin, remove excess oils, add missing oils, and apply the right amount of moisturizing compounds.

2) To protect the immune system by identifying unwanted bacteria and viruses and puncturing them to end their effectiveness.

3) To ensure that the right cells and supporting structures are at right place.

4) As a mouthwash to destroy pathogenic bacteria and lift food, plaque, or tartar from the teeth to rinse them away.

2) Actuators: Actuators are devices that put something (such as a robot arm) in action. They do so by converting electrical energy to mechanical energy. The direct conversion of electrical energy to mechanical energy through a material response is crucial for many biomedical applications such as microsurgical devices, artificial limbs, artificial ocular muscles, or pulsating hearts in addition to robotics, optical fiber devices, and optical displays. The main technical requirements of these actuators are low weight, low maintenance voltage, large displacements, high forces, fast response, and long cycle-life [120]. Different materials that have been previously investigated for use in electrochemical actuators are ceramics (piezoelectrics), shape memory alloys, and polymers. However, they have certain limitations. For example, piezoelectrics have low stiffness and electromechanical coupling coefficients.

Research reveals that CNTs can act as actuators [117], [120]-[123]. CNT actuators can work under physiological environment, low voltages, and temperatures as high as $350^{\circ} \mathrm{C}$. Nanotube-based polymer composites have promise as possible artificial muscle devices because of their incredible strength and stiffness in addition to relatively low operating voltage [195]. The mats of nanotubes expand and contract when operated as assembled electrodes in an electrochemical cell. When a potential is applied, charging of the electrodes takes place and there is a linear change in CNT length because of introduction of electronic charge on the tube and a restructuring of the double layer of charge in the double layer outside the tube [124]. The biocompatibility, crystallinity, and morphology of the composites were evaluated using SEM, TEM, hot stage microscopy, and polarized light. Also, thermal analysis was performed. Methods of characterization included thermal analysis using thermal gravimetric analysis (TGA) and differential scanning calorimetry (DSC). The results of all these analyses were promising [195].

Baughman et al. [117] were the first to evidence the actuator property of CNTs. They used actuators based on sheets of SWNTs. The CNT electromechanical actuators (also known as artificial muscles) generated higher stresses than natural muscles and higher strains than high-modulus ferroelectrics. MWNTs are excellent candidates for electromechanical devices because of their large surface area as well as their high electrical conductivity. Gao et al. [121] were the first to show an electromechanical actuator based on MWNTs. The actuator sheets were based on arrays of parallel nonbundled MWNTs whose tubes were perpendicular to the sheet planes. The MWNTs had a length $\sim 5-40 \mu \mathrm{m}$ and diameter 10-60 $\mathrm{nm}$. The actuators utilized the electrostatic repulsion between electrical 
double layers associated with parallel MWNTs. Vohrer et al. [120] developed an experimental setup for the measurement of the actuation forces and the displacement of CNT sheets for the first time. With their setup, vertical elongation or forces of bucky papers can be observed, which is a prerequisite for the optimization of artificial muscles for industrial applications. The fastest actuation time observed by them was approximately $3 \mathrm{~s}$.

The parameters that affect the electromechanical properties of CNT sheets are the used raw material (SWNTs and MWNTs; MWNTs have contorted structure compared to SWNTs), different production techniques (for example, arc-discharge material shows very low actuation), the purification grade (not only the amount of carbon particles but also the amount of remaining catalysts decrease the actuation time and actuation amplitude), the chirality and diameter of CNTs, the homogeneity of the nanotubes' distribution, alignment of the nanotubes, the size and thickness of the produced bucky paper (it was observed that thinner bucky papers react faster than thicker ones at comparable thickness values), type of electrolyte (chemistry, concentration, viscosity), electrode material, surface area of electrode, arrangement of electrodes, surface electrode resistance, applied voltage, and polarity [120].

3) Nanofluidic Systems: If the implantable fluid injection systems are large in size, functions of surrounding tissues are adversely affected. However, tiny nanodispensing systems can dispense drugs on demand using nanofluidic systems, miniaturized pumps, and reservoirs. Currently, limited attention has been given to understand the fluid mechanics at the nanoscale. As fluid mechanics at the nanoscale is in infant stage, there is a scarcity of experimental data [196]. The research so far reveals that MWNTs show great potential for use in nanofluidic devices. This can be attributed to their extremely high mechanical strength that is coupled with their ability to provide a conduit for fluid transport at near-molecular length scales. Furthermore, there is a lack of defects on their inner surface [197]. The nanodispensing systems using CNTs can be applied for chemotherapy where precise amounts of drugs are targeted directly at the tumors when the patient falls asleep. Other potential areas where fluid dispensing systems could be applied are lupus, AIDS, and diabetes [184].

\section{Surgical Aids}

Surgery using macro instruments can be cumbersome for both the surgeon and the patient. On one hand, the patient experiences severe pain, scarring, and high healing time because of large cuts; on the other hand, the surgeon requires high concentration for a long period to perform the surgery accurately. Sometimes, it may lead to surgical error due to the surgeon's fatigue. In many cases, surgical error may result because of the limited view of the organs by the surgeon. In addition, macro surgical instruments are not suitable for certain delicate cases such as surgeries related to heart, brain, eyes, and ears. One of the solutions is laparoscopic surgery, which uses a small entry port, long and narrow surgical instruments, and a rod-shaped telescope attached to a camera. However, laparoscopic surgery requires highly skilled surgeons for efficient surgery [184].
Research needs to be carried out to investigate if smart instruments (such as forceps, scalpels, and grippers with embedded sensors to provide improved functionality and real-time information) using CNTs can be developed that can aid surgeons by providing specific properties of tissue to be cut and provide information about performance of their instruments during surgery. The usefulness of CNTs for optically guiding surgery should also be investigated. This can lead to easy removal of tumors and other diseased sites. Another option is the use of molecular nanotechnology (MNT) or nanorobotics in surgery [198]. In nanorobotics, surgeons move joystick handles to manipulate robot arms containing miniature surgical instruments at the ports. Another robot arm contains a miniature camera for a broad view of the surgical site. It results in less stress for surgeons and less pain for patients; at the same time, high precision and safety is achieved. MNT allows in vivo surgery on individual human cells. Nanorobotics-based surgery can be used for gall bladder, cardiac, prostrate, bypass, colorectal, esophageal, and gynecological surgery [184]. However, nanorobotic systems for performing surgery require the ability to build precise structures, actuators, and motors that operate at molecular level to enable manipulation and locomotion [177]. As nanotweezers (that can be used for manipulation and modification of biological systems such as structures within a cell) have already been created using CNTs, they have the potential to be used in medical nanorobotics. Besides, Cumings and Zettl [199] have demonstrated that nested CNTs can make exceptionally low-friction nanobearings. These nanobearings can be used in many surgical tools. Therefore, research can be extended to investigate the application of CNTs in other surgical tools.

Although there may be a long process of getting some of the above-mentioned biomedical products to the market, the research on some of these aspects are already on the floor. In future, many of these developed devices could save millions of lives, and therefore gives companies and institutions the incentives to hasten their research.

\section{Challenges}

In a very short duration, CNTs appear to be the frontrunner that has the potential to dominate the biomedical research. However, there remain challenges that need to be addressed before the full potential of CNTs for biomedical applications can be realized. For example, there is a lack of detailed understanding of the growth mechanism of CNTs [200]. As a result, an efficient growth approach to structurally perfect nanotubes at large scales is currently not available. Second, it is difficult to grow defect-free nanotubes continuously to macroscopic lengths [33]. Third, control over nanotubes' growth on surfaces is required in order to obtain large-scale ordered nanowire structures [35]. Finally, controlling the chirality of SWNTs by any existing growth method is very difficult [33]. Also, the above-mentioned limitations result in high cost of production for pure and uncontaminated nanotubes with uniform characteristics. In short, the optimization of production parameters and the control on the growth of nanotubes is to be mastered.

In addition to the challenges at the fabrication level, the lowdimensional geometry results in structural instability, which is 
an important issue for the mechanical application of CNTs, as at larger strains they are prone to buckling, kink forming, and collapse [55]. Besides, the toxicology of CNTs is not well-understood. Dagani [201] compiled a report on the adverse effects at the blood-brain barrier of potential drug-carrying nanoparticles from the national meeting of the American Chemical Society. On the basis of their experiments, researchers suggested that CNTs possess health risks. They reasoned that humans can potentially be exposed to CNTs by inhalation because unprocessed CNTs are lightweight and, therefore, can become airborne. If CNTs reach the lung, they can agglomerate and fill the air passages, which may lead to suffocation. This warrants an in-depth study about the toxicology of CNTs to come up with a final conclusion with respect to their acceptance by the human immune system. Finally, the time from proof of concept in the laboratory of the CNT-based devices to the commercial marketplace should be reduced as the competition from other novel materials and technologies continue to emerge.

\section{CONCLUSION}

The past 13 years have seen phenomenal growth in the research activity in the area of CNTs. In this paper, we have made an effort to provide the most contemporary overview possible of synthesis, properties, and potential biomedical applications of CNTs through recent examples. The exceptional physical, mechanical, and electronic properties of CNTs allow them to be used in sensors, probes, actuators, nanoelectronic devices, and drug delivery systems within biomedical applications. With the increasing interest shown by the nanotechnology research community in this field, it is expected that plenty of applications of CNTs will be explored in future. At the same time, it is believed that the continued development and application of CNTs can enhance the practice of biomedical industries. However, amidst all the hope and hype, CNTs have yet to cross many technological hurdles in order to fulfill their potential as the most preferred material for biomedical applications. It is hoped that the descriptions provided and references to the literature therein will allow researchers to develop new applications besides proposing improvement in the current application areas.

\section{ACKNOWLEDGMENT}

The authors would like to thank Dr. D. Das, University of Ottawa, for the critical review of the manuscript. The authors would also like to thank Prof. O. Zhou for his help in the form of sending one of his papers related to dynamic radiography system.

\section{REFERENCES}

[1] T. R. Hsu, MEMS \& Microsystems: Design and Manufacture. Boston, MA: McGraw-Hill, 2002.

[2] M. Romero, R. Figueroa, and C. Madden. (2000) Pressure sensing systems for medical devices. Med. Dev. Diag. Ind. Mag. [Online]. Available: http://www.devicelink.com/mddi/archive/00/10/004.html

[3] S. Ijima, "Helical microtubules of graphitic carbon," Nature, vol. 354, pp. 56-58, 1991.

[4] M. S. Dresselhaus, "Fullerenes: Down the straight and narrow," Nature, vol. 358, pp. 195-196, 1992.

[5] M. S. Dresselhaus, G. Dresselhaus, and P. C. Eklund, Science of Fullerenes and Carbon Nanotubes. New York: Academic, 1996.
[6] Lawrence Berkley Nat. Labs [Online]. Available: http://www.lbl.gov

[7] Y. Cheng and O. Zhou, "Electron field emission from carbon nanotubes," C.R. Physique, vol. 4, pp. 1021-1033, 2003.

[8] S. Ijima, P. M. Ajayan, and T. Ichihashi, "Growth model for carbon nanotubes," Phys. Rev. Lett., vol. 69, no. 21, pp. 3100-3103, 1992.

[9] T. W. Ebbesen and P. M. Ajayan, "Large scale synthesis of carbon nanotubes," Nature, vol. 358, pp. 220-221, 1992.

[10] S. Ijima and T. Ichihashi, "Single-shell carbon nanotubes of 1-nm diameter," Nature, vol. 363, p. 603, 1993.

[11] D. S. Bethune, C. H. Kiang, M. S. de Vries, G. Gorman, R. Savoy, J. Vazquez, and R. Beyers, "Cobalt-catalyzed growth of carbon nanotubes with single-atomic-layer walls," Nature, vol. 363, p. 305, 1993.

[12] C. Liu, H. T. Cong, F. Li, P. H. Tan, H. M. Cheng, K. Lu, and B. L. Zhou, "Semi-continuous synthesis of single-walled carbon nanotubes by a hydrogen arc discharge method," Carbon, vol. 37, no. 11, pp. 1865-1868, 1999.

[13] M. V. Antisari, R. Marazzi, and R. Krsmanovic, "Synthesis of multiwall carbon nanotubes by electric arc discharge in liquid environments," Carbon, vol. 41, no. 12, pp. 2393-2401, 2003.

[14] H. Zhu, B. Jiang, C. Xu, and D. Wu, "Synthesis of high quality singlewalled carbon nanotube silks by the arc discharge technique," J. Phys. Chem. B, vol. 107, no. 27, pp. 6514-6518, 2003.

[15] H. Li, L. Guan, Z. Shi, and Z. Gu, "Direct synthesis of high purity singlewalled carbon nanotube fibers by arc discharge," J. of Phys. Chem. B, vol. 108, no. 15, pp. 4573-4575, 2004.

[16] C. Journet, W. K. Maser, P. Bernier, A. Loiseau, M. L. de la Chapelle, S. Lefrant, P. Deniard, R. Lee, and J. E. Fischer, "Large-scale production of single-walled carbon nanotubes by the electric-arc technique," Nature, vol. 388, pp. 756-758, 1997.

[17] A. Thess, R. Lee, P. Nikolaev, H. J. Dai, P. Petit, J. Robert, C. H. Xu, Y. H. Lee, S. G. Kim, A. G. Rinzler, D. T. Colbert, G. E. Scuseria, D. Tomanek, J. E. Fischer, and R. E. Smalley, "Crystalline ropes of metallic carbon nanotubes," Science, vol. 273, no. 5274, pp. 483-487, 1996

[18] N. Braidy, M. A. El Khakani, and G. A. Botton, "Carbon nanotubular structures synthesis by means of ultraviolet laser ablation," J. Mater. Res., vol. 17, no. 9, pp. 2189-2192, 2002.

[19] S. Takahashi, T. Ikuno, T. Oyama, S. I. Honda, M. Katayama, T. Hirao, and K. Oura, "Synthesis and characterization of carbon nanotubes grown on carbon particles by using high vacuum laser ablation," J. Vac. Soc. Jpn., vol. 45, no. 7, pp. 609-612, 2002.

[20] R. L. Vanderwal, G. M. Berger, and T. M. Ticich, "Carbon nanotube synthesis in a flame using laser ablation for in situ catalyst generation," Appl. Phys. A, vol. 77, no. 7, pp. 885-889, 2003.

[21] M. J. Yacaman, M. M. Yoshida, L. Rendon, and J. G. Santiesteban, "Catalytic growth of carbon microtubules with fullerene structure," Appl. Phys. Lett., vol. 62, pp. 202-204, 1993.

[22] W. Z. Li, S. S. Xie, L. X. Qian, B. H. Chang, B. S. Zou, W. Y. Zhou, R A. Zhao, and G. Wang, "Large-scale synthesis of aligned carbon nanotubes," Science, vol. 274, no. 5293, pp. 1701-1703, 1996.

[23] L. C. Qin, "CVD synthesis of carbon nanotubes," J. Mater. Sci. Lett., vol. 16, no. 6, pp. 457-459, 1997.

[24] Y. C. Choi, D. J. Bae, Y. H. Lee, B. S. Lee, G. S. Park, W. B. Choi, N. S. Lee, and J. M. Kim, "Growth of carbon nanotubes by microwave plasma-enhanced chemical vapor deposition at low temperature," J. Vac. Sc. Technol. A, vol. 18, no. 4, pp. 1864-1868, 2000.

[25] V. K. Varadan and J. Xie, "Large-scale synthesis of multiwalled carbon nanotubes by microwave CVD," Smart Mater. Struct., vol. 11, no. 4, pp. 610-616, 2002.

[26] A. K. Chatterjee, M. Sharon, R. Banerjee, and M. Neumann-Spallart, "CVD synthesis of carbon nanotubes using a finely dispersed cobalt catalyst and their use in double layer electrochemical capacitors," Electrochimica Acta, vol. 48, no. 23, pp. 3439-3446, 2003.

[27] D. Park, Y. H. Kim, and J. K. Lee, "Synthesis of carbon nanotubes on metallic substrates by a sequential combination of PECVD and thermal CVD," Carbon, vol. 41, no. 5, pp. 1025-1029, 2003.

[28] S. Chaisitsak, A. Yamada, and M. Konagai, "Hot filament enhanced CVD synthesis of carbon nanotubes by using a carbon filament," $D i$ amond Relat. Mater., vol. 13, no. 3, pp. 438-444, 2004.

[29] K. Mukhopadhyay, D. Lal, K. Ram, and G. N. Mathur, "Synthesis of two dimensional quasi-aligned carbon nanotube bundles by a catalytic chemical vapor deposition method-an inside story," Smart Mater. Struct., vol. 13, no. 1, pp. N5-N8, 2004.

[30] R. Seidel, G. S. Duesberg, E. Unger, A. P. Graham, M. Liebau, and F. Kreupl, "Chemical vapor deposition growth of single-walled carbon nanotubes at $600{ }^{\circ} \mathrm{C}$ and a simple growth model," J. Phys. Chem. B, vol. 108, no. 6, pp. 1888-1893, 2004. 
[31] J. K. Vohs, J. J. Brege, J. E. Raymond, A. E. Brown, G. L. Williams, and B. D. Fahlman, "Low-temperature growth of carbon nanotubes from the catalytic decomposition of carbon tetrachloride," J. Amer. Chem. Soc., vol. 126, no. 32, pp. 9936-9937, 2004.

[32] T. W. Ebbesen, "Production and purification of carbon nanotubes," in Carbon Nanotubes: Preparation and Properties, T. W. Ebbesen, Ed. Boca Raton, FL: CRC, 1997, pp. 139-162.

[33] H. Dai, "Nanotube growth and characterization," Top. Appl. Phys., vol. 80, pp. 29-54, 2001.

[34] V. N. Popov, "Carbon nanotubes: Properties and application," Mater. Sci. Eng. R: Rep., vol. 43, no. 3, pp. 61-102, 2004.

[35] H. Dai, "Carbon nanotubes: Opportunities and challenges," Surf. Sci., vol. 500, no. 1-3, pp. 218-241, 2002.

[36] L. Thien-Nga, J. M. Bonard, R. Gaal, and L. Forro, "Comparison of catalytically grown and Ar-discharge carbon nanotube tips," Appl. Phys. Lett., vol. 80, no. 5, pp. 850-852, 2002.

[37] T. W. Ebbesen, P. M. Ajayan, H. Hiura, and K. Tanigaki, "Purification of nanotubes," Nature, vol. 367, p. 519, 1994.

[38] S. Gajewski, H. E. Maneck, U. Knoll, D. Neubert, I. Dorfel, R. Mach, B. Strauss, and J. F. Friedrich, "Purification of single walled carbon nanotubes by thermal gas phase oxidation," Diamond Relat. Mater., vol. 12, no. 3-7, pp. 816-820, 2003.

[39] H. Hiura, T. W. Ebbesen, and K. Tanigaki, "Opening and purification of carbon nanotubes in high yields," Adv. Mater, vol. 7, no. 3, pp. 275-276, 1995.

[40] L. Vaccarini, C. Goze, R. Aznar, V. Micholet, C. Journet, and P. Bernier, "Purification procedure of carbon nanotubes," Synth. Met., vol. 103, no. 1-3, pp. 2492-2493, 1999.

[41] H. Y. Kim, W. B. Choi, N. S. Lee, D. S. Chung, J. H. Kang, I. T. Han, J. M. Kim, M. H. Moon, and J. S. Kim, "Purification and characterization of single-walled carbon nanotubes," in Proc. Materials Research Soc. Symp., vol. 593, 2000, pp. 123-127.

[42] S. Bandow, A. M. Rao, K. A. Williams, A. Thess, R. E. Smalley, and P. C. Eklund, "Purification of single-wall carbon nanotubes by microfiltration," J. Phys. Chem. B, vol. 101, no. 44, pp. 8839-8842, 1997.

[43] C. Xu, E. Flahaut, S. R. Bailey, G. Brown, J. Sloan, K. S. Coleman, V. C. Williams, and M. L. H. Green, "Purification of single-walled carbon nanotubes grown by a chemical vapor deposition (CVD) method," Chem. Res. Chinese Univ., vol. 18, no. 2, pp. 130-132, 2002.

[44] L. P. Biro, N. Q. Khanh, Z. Vertesy, Z. E. Horvath, Z. Osvath, A. Koos, J. Gyulai, A. Kocsonya, Z. Konya, X. B. Zhang, G. V. Tendeloo, A. Fonseca, and J. B. Nagy, "Catalyst traces and other impurities in chemically purified carbon nanotubes grown by CVD," Mater. Sci. Eng. C, vol. C19, pp. 9-13, 2002.

[45] K. B. Shelimov, R. O. Esenaliev, A. G. Rinzler, C. B. Huffman, and R. E. Smalley, "Purification of single-wall carbon nanotubes by ultrasonically assisted filtration," Chem. Phys. Lett., vol. 282, no. 5-6, pp. 429-434, 1998.

[46] E. Dujardin, T. W. Ebbesen, A. Krishnan, and M. M. J. Treacy, "Purification of single-shell nanotubes," Adv. Mater, vol. 10, no. 8, pp. 611-613, 1998.

[47] A. R. Harutyunyan, B. K. Pradhan, J. Chang, G. Chen, and P. C. Eklund, "Purification of single-wall carbon nanotubes by selective microwave heating of catalyst particles," J. Phys. Chem. B, vol. 106, pp. 8671-8675, 2002.

[48] C. J. Ko, C. Y. Lee, F. H. Ko, H. L. Chen, and T. C. Chu, "Highly efficient microwave-assisted purification of multiwalled carbon nanotubes," Microelec. Eng., vol. 73-74, pp. 570-577, 2004.

[49] E. W. Wong, P. E. Sheehan, and C. M. Lieber, "Nanobeam mechanics: Elasticity, strength, and toughness of nanotubes and nanorods," Science, vol. 277, pp. 1971-1975, 1997.

[50] R. Saito, M. Fujita, G. Desselhaus, and M. S. Dresselhaus, "Electronic structure of chiral graphene tubules," Appl. Phys. Lett., vol. 60, no. 18, pp. 2204-2206, 1992.

[51] R. H. Baughman, A. A. Zakhidov, and W. A. de Heer, "Carbon nanotubes-the route toward applications," Science, vol. 297, no. 5582, pp. 787-792, 2002.

[52] M. Terrones, "Science and technology of the twenty-first century: Synthesis, properties, and applications of carbon nanotubes," Ann. Rev. Mater. Res., vol. 33, pp. 419-501, 2003.

[53] M. S. Dresselhaus, P. C. Eklund, and R. Saito, "Carbon nanotubes," Phys. World, vol. 33, 1998.

[54] S. G. Louie, "Electronic properties, junctions, and defects of carbon nanotubes," Top. Appl. Phys., vol. 80, pp. 113-146, 2001.

[55] R. S. Ruoff, D. Qian, and W. K. Liu, "Mechanical properties of carbon nanotubes: Theoretical predictions and experimental measurements," C.R. Physique, vol. 4, pp. 993-1008, 2003.
[56] S. Amelinckx, D. Bernaerts, X. B. Zhang, G. van Tendeloo, and J. van Landuyt, "A structure model and growth mechanism for multishell carbon nanotubes," Science, vol. 267, no. 5202, pp. 1334-1338, 1995.

[57] W. Liang, M. Bockrath, D. Bozovic, J. H. Hafner, M. Tinkham, and H. Park, "Fabry-Perot interference in a nanotube electron waveguide," $\mathrm{Na}$ ture, vol. 411, pp. 665-669, 2001.

[58] P. Lambin, J. P. Vigneron, A. Fonseca, J. B. Nagy, and A. A. Lucas, "Atomic structure and electronic properties of a bent carbon nanotube," Synth. Met., vol. 77, pp. 249-252, 1996.

[59] L. Chico, V. H. Crespi, L. X. Benedict, S. G. Louie, and M. L. Cohen, "Pure carbon nanoscale devices: Nanotube heterojunctions," Phys. Rev. Lett., vol. 76, no. 6, pp. 971-974, 1996.

[60] A. Rochefort, D. R. Salahub, and P. Avouris, "The effect of structural distortions on the electronic structure of carbon nanotubes," Chem. Phys. Lett., vol. 297, pp. 45-50, 1998.

[61] A. Rochefort, P. Avouris, F. Lesage, and D. R. Salahub, "Electrical and mechanical properties of distorted carbon nanotubes," Phys. Rev. B, vol. 60, pp. 13824-13830, 1999.

[62] M. Kociak, A. Y. Kasimov, S. Gueron, B. Reulet, I. I. Khodos, Y. B. Gorbatov, V. T. Volkov, L. Vaccarini, and H. Bouchiat, "Superconductivity in ropes of single-walled carbon nanotubes," Phys. Rev. Lett., vol. 86, no. 11 , pp. 2416-2419, 2001.

[63] M. M. J. Treacy, T. W. Ebbesen, and J. M. Gibson, "Exceptionally high young's modulus observed for individual carbon nanotubes," Nature, vol. 381, pp. 678-680, 1996.

[64] M. R. Falvo, G. J. Clary, R. M. Taylor, V. Chi, F. P. Brooks, S. Washburn, and R. Superfine, "Bending and buckling of carbon nanotubes under large strain," Nature, vol. 389, pp. 582-584, 1997.

[65] O. Lourie and H. D. Wagner, "Evaluation of young's modulus of carbon nanotubes by micro-raman spectroscopy," J. Mater. Res., vol. 13, no. 9, pp. 2418-2422, 1998.

[66] M. F. Yu, B. S. Files, S. Arepalli, and R. S. Ruoff, "Tensile loading of ropes of single wall carbon nanotubes and their mechanical properties," Phys. Rev. Lett., vol. 84, no. 24, pp. 5552-5555, 2000.

[67] M. F. Yu, O. Lourie, M. J. Dyer, K. Moloni, T. F. Kelly, and R. S. Ruoff, "Strength and breaking mechanism of multiwalled carbon nanotubes under tensile load," Science, vol. 287, no. 5453, pp. 637-640, 2000.

[68] O. Lourie, D. M. Cox, and H. D. Wagner, "Buckling and collapse of embedded carbon nanotubes," Phys. Rev. Lett., vol. 81, no. 8, pp. 1638-1641, 1998.

[69] T. Belytschko, S. P. Xiao, G. C. Schartz, and R. S. Ruoff, "Atomistic simulation of nanotube fracture," Phys. Rev. B, vol. 65, p. 235 430, 2002.

[70] P. H. Zhang, P. E. Lammert, and V. H. Crespi, "Plastic deformations of carbon nanotubes," Phys. Rev. Lett., vol. 81, no. 24, pp. 5346-5349, 1998.

[71] J. P. Salvetat, J. M. Bonard, N. H. Thomson, A. J. Kulik, L. Forro, W. Benoit, and L. Zuppiroli, "Mechanical properties of carbon nanotubes," Appl. Phys. A, vol. 69, pp. 255-260, 1999.

[72] M. B. Nardelli, B. I. Yakobson, and J. Bernholc, "Mechanism of strain release in carbon nanotubes," Phys. Rev. B, vol. 57, no. 8, p. R4277, 1998.

[73] J. Hone, M. C. Llaguno, N. M. Nemes, A. T. Johnson, J. E. Fischer, D. A. Walters, M. J. Casavant, J. Schmidt, and R. E. Smalley, "Electrical and thermal transport properties of magnetically aligned single wall carbon nanotube films," Appl. Phys. Lett., vol. 77, no. 5, pp. 666-668, 2000.

[74] W. Yi, L. Lu, D. L. Zhang, Z. W. Pan, and S. S. Xie, "Linear specific heat of carbon nanotubes," Phys. Rev. B, vol. 59, p. R9015, 1999.

[75] A. Mizel, L. X. Benedict, M. L. Cohen, S. G. Louie, A. Zettl, N. K. Budraa, and W. P. Beyermann, "Analysis of the low-temperature specific heat of multiwalled carbon nanotubes and carbon nanotube ropes," Phys. Rev. B, vol. 60, p. 3264, 1999.

[76] J. C. Lasjaunias, K. Biljakoviae, Z. Benes, J. E. Fischer, and P. Monceau, "Low-temperature specific heat of single-wall carbon nanotubes," Phys. Rev. B, vol. 65, p. $113409,2002$.

[77] J. Hone, M. Whitney, C. Piskoti, and A. Zettl, "Thermal conductivity of single-walled carbon nanotubes," Phys. Rev. B, vol. 59, no. 4, p. R2514, 1999.

[78] W. Zhang, Z. Zhu, F. Wang, T. Wang, L. Sun, and Z. Wang, "Chirality dependence of the thermal conductivity of carbon nanotubes," Nanotechnology, vol. 15, pp. 936-939, 2004.

[79] P. Kim, L. Shi, A. Majumdar, and P. L. McEuen, "Thermal transport measurements of individual multiwalled nanotubes," Phys. Rev. Lett., vol. 87, no. 21, p. $215502,2001$.

[80] P. M. Ajayan and O. Zhou, "Applications of carbon nanotubes," Top. Appl. Phys., vol. 80, pp. 391-425, 2001.

[81] W. A. de Heer, "Nanotubes and the pursuit of applications," MRS Bulletin: Adv. Carbon Nanotubes, vol. 29, no. 4, p. 281, 2004. 
[82] C. Niu, E. K. Sichel, R. Hoch, D. Moy, and H. Tennent, "High power electrochemical capacitors based on carbon nanotube electrodes," Appl. Phys. Lett., vol. 70, no. 11, pp. 1480-1482, 1997.

[83] G. Che, B. B. Lakshmi, E. R. Fisher, and C. R. Martin, "Carbon nanotube membranes for electrochemical energy storage and production," Nature, vol. 393, no. 6683, pp. 346-349, 1998.

[84] E. Frackowiak and F. Beguin, "Electrochemical storage of energy in carbon nanotubes and nanostructured carbons," Carbon, vol. 40, no. 10, pp. 1775-1787, 2002.

[85] Q. Xiao and X. Zhou, "The study of multiwalled carbon nanotube deposited with conducting polymer for supercapacitor," Electr. Acta, vol. 48 , no. 5, pp. 575-580, 2003.

[86] T. Liu, S. Kumar, R. H. Hauge, R. E. Smalley, and T. V. Sreekumar, "SWNT/PAN composite film-based supercapacitors," Carbon, vol. 41, no. 12 , pp. $2440-2442,2003$

[87] F. Pico, J. M. Rojo, M. L. Sanjuan, A. Anson, A. M. Benito, M. A. Callejas, W. K. Maser, and M. T. Martinez, "Single-walled carbon nanotube as electrodes in capacitors," J. Electrochem. Soc., vol. 151, no. 6, pp. A831-A837, 2004.

[88] C. Bower, R. Rosen, J. Lin, J. Han, and O. Zhou, "Deformation of carbon nanotubes in nanotube-polymer composites," Appl. Phys. Lett., vol. 74, no. 22, pp. 3317-3319, 1999.

[89] P. Calvert, "Nanotube composites: A recipe for strength," Nature, vol. 399, pp. 210-211, 1999.

[90] K. T. Lau and D. Hui, "The revolutionary creation of new advanced materials-carbon nanotube composites," Composites B: Eng., pp. 263-277, 2002.

[91] F. D. S. Marquis, "Fully integrated hybrid polymeric carbon nanotube composites," Mater. Sci. Forum, vol. 437-438, pp. 85-88, 2003.

[92] Z. Bian, R. H. Wang, W. H. Wang, T. Zhang, and A. Inoue, "Carbon nanotube reinforced Zr-based bulk metallic glass composites and their properties," Adv. Func. Mater., vol. 14, no. 1, pp. 55-63, 2004.

[93] E. Flahaut, S. Rul, F. Lefevre-Schlick, C. Laurent, and A. Peigney, "Carbon nanotubes-ceramic composites," Ceramic Trans., vol. 148, pp. 71-82, 2004.

[94] T. Noguchi, A. Magario, S. Fukazawa, S. Shimizu, J. Beppu, and M. Seki, "Carbon nanotube/aluminum composites with uniform dispersion," Mater. Trans., vol. 45, no. 2, pp. 602-604, 2004.

[95] H. Dai, J. H. Hafner, A. G. Rinzler, D. T. Colbert, and R. E. Smalley, "Nanotubes as nanoprobes in scanning probe microscopy," Nature, vol. 384, pp. 147-150, 1996.

[96] P. G. Collins, K. Bradley, M. Ishigami, and A. Zettl, "Extreme oxygen sensitivity of electronic properties of carbon nanotubes," Science, vol. 287, pp. 1801-1804, 2000.

[97] J. Kong, N. R. Franklin, C. Zhou, M. G. Chapline, S. Peng, K. Cho, and H. Dai, "Nanotube molecular wires as chemical sensors," Science, vol. 287, pp. 622-625, 2000.

[98] J. R. Wood and H. D. Wagner, "Single-wall carbon nanotubes as molecular pressure sensors," Appl. Phys. Lett., vol. 76, no. 20, pp. 2883-2885, 2000

[99] J. Liu and H. Dai. (2002) Design, fabrication, and testing of piezoresistive pressure sensors using carbon nanotubes. [Online]. Available: http://www.nnf.cornell.edu/2002re u/ Liu.pdf

[100] R. Caldwell, H. Dai, Q. Wang, and R. Grow. (2002) Carbon nanotubes as piezoresistors for a pressure sensor. [Online]. Available: http://www.nnf.cornell.edu/2002re u/Caldwell.pdf

[101] K. G. Ong, K. Zeng, C. A. Grimes, and A. Wireless, "Passive carbon nanotube-based gas sensor," IEEE Sensors J., vol. 2, no. 2, pp. 82-88, Apr. 2002.

[102] S. Chopra, K. McGuire, N. Gothard, and A. M. Rao, "Selective gas detection using a carbon nanotube sensor," Appl. Phys. Lett., vol. 83, no. 11, pp. 2280-2282, 2003.

[103] C. K. M. Fung and W. J. Li, "Ultra-low-power and high-frequency-response carbon nanotube based MEMS thermal sensors," in Proc. IEEE Int. Conf. Intelligent Robots and Systems, vol. 3, 2003, pp. 2371-2376.

[104] S. Ghosh, A. K. Sood, and N. Kumar, "Carbon nanotube flow sensors," Science, vol. 299, no. 5609, pp. 1042-1044, 2003.

[105] K. J. Liao, W. L. Wang, Y. Zhang, L. H. Duan, and Y. Ma, "Experimental studies on flow velocity sensors based on multiwalled carbon nanotubes," Microfab. Technol., vol. 4, p. 57, 2003.

[106] S. Sotiropoulou and N. A. Chaniotakis, "Carbon nanotube array-based biosensor," Anal. Bioanal. Chem., vol. 375, pp. 103-105, 2003.

[107] A. Modi, N. Koratkar, E. Lass, B. Wei, and P. M. Ajayan, "Miniaturized gas ionization sensors using carbon nanotubes," Nature, vol. 424, pp. 171-174, 2003.
[108] A. Callegari, S. Cosnier, M. Marcaccio, D. Paolucci, F. Paolucci, V. Georgakilas, N. Tagmatarchis, E. Vazquez, and M. Prato, "Functionalized single wall carbon nanotubes/polypurrole composites for the preparation of amperometric glucose biosensors," J. Mater. Chem., vol. 14, no. 5, pp. 807-810, 2004

[109] P. Dharap, Z. Li, S. Nagarajaiah, and E. V. Barrera, "Nanotube film based on single-wall carbon nanotubes for strain sensing," Nanotechnology, vol. 15, no. 3, pp. 379-382, 2004.

[110] T. S. Huang, Y. Tzeng, Y. K. Liu, Y. C. Chen, K. R. Walker, R. Guntupalli, and C. Liu, "Immobilization of antibodies and bacterial binding on nanodiamond and carbon nanotubes for biosensor applications," $\mathrm{Di}$ amond Relat. Mater., vol. 13, no. 4-8, pp. 1098-1102, 2004.

[111] Y. T. Jang, S. Moon, J. H. Ahn, Y. H. Lee, and B. K. Ju, "A simple approach in fabricating chemical sensor using laterally grown multiwalled carbon nanotubes," Sens. Actuators B, vol. 99, no. 1, pp. 118-122, 2004.

[112] K. P. Loh, S. L. Zhao, and W. D. Zhang, "Diamond and carbon nanotube glucose sensors based on electropolymerization," Diamond Relat. Mater., vol. 13, no. 4-8, pp. 1075-1079, 2004.

[113] R. Mateiu, Z. J. Davis, D. N. Madsen, K. Molhave, P. Boggild, A. M. Rassmusen, M. Brorson, C. J. H. Jacobsen, and A. Boisen, "An approach to a multiwalled carbon nanotube based mass sensor," Microelec. Eng., vol. 73-74, pp. 670-674, 2004.

[114] M. Penza, F. Antolini, and M. V. Antisari, "Carbon nanotubes as SAW chemical sensors materials," Sens. Actuators B, vol. 100, no. 1-2, pp. 47-59, 2004.

[115] L. Valentini, C. Cantalini, I. Armentano, J. M. Kenny, L. Lozzi, and S. Santucci, "Highly sensitive and selective sensors based on carbon nanotubes thin films for molecular detection," Diamond Relat. Mater., vol. 13, no. 4-8, pp. 1301-1305, 2004

[116] J. Wu, J. Zang, B. Larade, H. Guo, X. G. Gong, and F. Liu, "Computational design of carbon nanotube electromechanical pressure sensors,' Phys. Rev. B, vol. 69, p. 153 406, 2004.

[117] R. H. Baughman, C. Cui, A. A. Zakhidov, Z. Iqbal, J. N. Barisci, G. M. Spinks, G. G. Wallace, A. Azzoldi, D. De Rossi, A. G. Rinzler, O. Jaschinski, S. Roth, and M. Kertesz, "Carbon nanotube actuators," Science, vol. 284, pp. 1340-1344, 1999.

[118] A. M. Fennimore, T. D. Yuzvinsky, W. Q. Han, M. S. Fuhrer, J. Cumings, and A. Zettl, "Rotational actuators based on carbon nanotubes," Nature, vol. 424, pp. 408-410, 2003.

[119] G. Gu, M. Schmid, P. W. Chiu, A. Minett, J. Fraysse, G. T. Kim, S. Roth, M. Kozlov, E. Munoz, and R. H. Baughman, "V2O5 nanofiber sheet actuators," Nature Mater, vol. 2, pp. 316-319, 2003.

[120] U. Vohrer, I. Kolaric, M. H. Haque, S. Roth, and U. Detlaff-Weglikowska, "Carbon nanotube sheets for use as artificial muscles," Carbon, vol. 42, pp. 1159-1164, 2004.

[121] M. Gao, L. Dai, R. H. Baughman, G. M. Spinks, and G. G. Wallace, "Electrochemical properties of aligned nanotube arrays: Basis of new electromechanical actuators," Proc. SPIE, vol. 3987, pp. 18-24, 2000.

[122] J. Fraysse, A. I. Minett, O. Jaschinski, G. S. Duesberg, and S. Roth, "Carbon nanotubes acting like actuators," Carbon, vol. 40, pp. 1735-1739, 2002.

[123] H. P. Monner, S. Muhle, and P. Wierach, "Carbon nanotubes as actuators in smart structures," in Proc. SPIE, vol. 5053, 2003, pp. 138-146.

[124] O. Inganas and I. Lundstrum, "Carbon nanotube muscles," Science, vol. 284, no. 5418, pp. 1281-1282, 1999.

[125] Q. H. Wang, A. A. Setlur, J. M. Lauerhaas, J. Y. Dai, E. W. Seelig, and R. P. H. Chang, "A nanotube-based field-emission flat panel display," Appl. Phys. Lett., vol. 72, no. 22, pp. 2912-2913, 1998.

[126] Z. Yao, H. W. C. Postma, L. Balents, and C. Dekker, "Carbon nanotube intramolecular junctions," Nature, vol. 402, pp. 273-276, 1999.

[127] R. Rosen, W. Simendinger, C. Debbault, H. Shimoda, L. Fleming, B. Stoner, and O. Zhou, "Application of carbon nanotubes as electrodes in gas discharge tubes," Appl. Phys. Lett., vol. 76, no. 13, pp. 1668-1670, 2000.

[128] Y. Saito and S. Uemura, "Field emission from carbon nanotubes and its application to electron sources," Carbon, vol. 38, no. 2, pp. 169-182, 2000.

[129] Y. Nakayama and S. Akita, "Field-emission device with carbon nanotubes for a flat panel display," Synth. Met., vol. 117, no. 1-3, pp 207-210, 2001.

[130] R. Collazo, R. Schlesser, and Z. Sitar, "Field emission from carbon nanotubes," New Diamond Frontier Carbon Technol., vol. 13, no. 5, pp. 297-306, 2003.

[131] W. I. Milne, K. B. K. Teo, G. A. J. Amaratunga, P. Legagneux, L. Gangloff, J. P. Schnell, V. Semet, V. T. Binh, and O. Groening, "Carbon nanotubes as field emission sources," J. Mater. Chem., vol. 14, no. 6, pp. 933-943, 2004. 
[132] R. C. Smith, J. D. Carey, C. H. P. Poa, D. C. Cox, and S. R. P. Silva, "Electron field emission from room temperature grown carbon nanofibers," J. Appl. Phys., vol. 95, no. 6, pp. 3153-3157, 2004.

[133] M. Sveningsson, R. E. Morjan, O. Nerushev, and E. E. B. Campbell, "Electron field emission from multiwalled carbon nanotubes," Carbon, vol. 42, no. 5-6, pp. 1165-1168, 2004.

[134] J. Wei, H. Zhu, D. Wu, and B. Wei, "Carbon nanotube filaments in household light bulbs," Appl. Phys. Lett., vol. 84, no. 24, pp. 4869-4871, 2004.

[135] H. Dai, E. W. Wong, Y. Z. Lu, S. Fan, and C. M. Lieber, "Synthesis and characterization of carbide nanorods," Nature, vol. 375, pp. 769-772, 1995.

[136] W. Han, S. Fan, Q. Li, and Y. Hu, "Synthesis of gallium nitride nanorods through a carbon nanotube-confined reaction," Science, vol. 277, pp. 1287-1289, 1997.

[137] X. R. Ye, Y. Lin, C. Wang, and C. M. Wai, "Supercritical fluid fabrication of metal nanowires and nanorods templated by multiwalled carbon nanotubes," Adv. Mater., vol. 15, no. 4, pp. 316-319, 2003.

[138] H. Q. Wu, X. W. Wei, M. W. Shao, and J. S. Gu, "Synthesis of zinc oxide nanorods using carbon nanotubes as templates," J. Cryst. Growth, vol. 265, pp. 184-189, 2004.

[139] V. Lordi, N. Yao, and J. Wei, "Method for supporting platinum on singlewalled carbon nanotubes for a selective hydrogenation catalyst," Chem. Mater, vol. 13, no. 3, pp. 733-737, 2001.

[140] D. T. Mitchell, S. B. Lee, L. Trofin, N. Li, T. K. Nevanen, H. Soderlund, and C. R. Martin, "Smart nanotubes for bioseparations and biocatalysis," J. Amer. Chem. Soc., vol. 124, pp. 11864-11865, 2002.

[141] M. J. Ledoux, R. Vieira, C. P. Huu, and N. Keller, "New catalytic phenomena on nanostructured (fibers and tubes) catalysts," J. Catalysis, vol. 216, pp. 333-342, 2003.

[142] P. Serp, M. Corrias, and P. Kalck, "Carbon nanotubes and nanofibers in catalysis," Appl. Catalysis A, vol. 253, no. 2, pp. 337-358, 2003.

[143] C. Baleizao, B. Gigante, H. Garcia, and A. Corma, "Vanadyl salen complexes covalently anchored to single-wall carbon nanotubes as heterogeneous catalysts for the cyanosilylation of aldehydes," J. Catalysis, vol. 221, pp. 77-84, 2004.

[144] Y. Wang, S. Da, M. J. Kim, K. F. Kelly, W. Guo, C. Kittrell, R. H. Hauge, and R. E. Smalley, "Ultrathin 'bed-of-nails' membranes of single-wall carbon nanotubes," J. Amer. Chem. Soc., vol. 126, pp. 9502-9503, 2004.

[145] G. G. Tibbetts, G. P. Meisner, and C. H. Olk, "Hydrogen storage capacity of carbon nanotubes, filaments, and vapor-grown fibers," Carbon, vol. 39, no. 15, pp. 2291-2301, 2001.

[146] A. C. Dillon and M. J. Heben, "Hydrogen storage using carbon adsorbents: Past, present, and future," Appl. Phys. A, vol. 72, pp. 133-142, 2001.

[147] V. V. Simonyan and J. K. Johnson, "Hydrogen storage in carbon nanotubes and graphitic nanofibers," J. Alloys Compounds, vol. 330-332, pp. 659-665, 2002.

[148] A. Fonseca, N. Pierard, S. Tollis, G. Bister, Z. Konya, N. Nagaraju, and J. B. Nagy, "Hydrogen storage in carbon nanotubes produced by CVD," J. De Phys., vol. 12, no. 4, pp. Pr4/129-Pr4/137, 2002.

[149] H. Gao, X. B. Wu, J. T. Li, G. T. Wu, J. Y. Lin, K. Wu, and D. S. Xu, "Hydrogen adsorption of open-tipped insufficiently graphitized multiwalled carbon nanotubes," Appl. Phys. Lett., vol. 83, no. 16, pp. 3389-3391, 2003.

[150] J. Lawrence and G. Xu, "High pressure saturation of hydrogen stored by single-wall nanotubes," Appl. Phys. Lett., vol. 84, no. 6, pp. 918-920, 2004.

[151] D. Luxembourg, G. Flamant, A. Guillot, and D. Laplaze, "Hydrogen storage in solar produced single-walled carbon nanotubes," Mater. Sci. Eng. B: Solid-State Mater. Adv. Technol., vol. 108, no. 1-2, pp. 114-119, 2004.

[152] G. Z. Yue, Q. Qiu, B. Gao, Y. Cheng, J. Zhang, H. Shimoda, S. Chang, J. P. Lu, and O. Zhou, "Generation of continuous and pulsed diagnostic imaging X-ray radiation using a carbon-nanotube-based field-emission cathode," Appl. Phys. Lett., vol. 81, no. 2, pp. 355-357, 2002.

[153] I. Brodie and P. R. Schwoebel, "Vacuum microelectronic devices," Proc. IEEE, vol. 82, no. 7, pp. 1006-1034, Jul. 1994.

[154] Y. Saito, K. Hamaguchi, K. Hata, K. Uchida, Y. Tasaka, F. Ikazaki, M. Yumura, A. Kasuya, and Y. Nishina, "Conical beams from open nanotubes," Nature, vol. 389, pp. 554-555, 1997.

[155] J. M. Bonard, T. Stockli, F. Maier, W. A. de Heer, and A. Chatelain, "Field-emission-induced luminescence from carbon nanotubes," Phys. Rev. Lett., vol. 81, no. 7, pp. 1441-1444, 1998.

[156] A. de Vita, J. C. Charlier, X. Blasé, and R. Car, "Electronic structure at carbon nanotube tips," Appl. Phys. A, vol. 68, pp. 283-286, 1999.
[157] Y. Cheng, J. Zhang, Y. Z. Lee, B. Gao, S. Dike, W. Lin, J. P. Lu, and O. Zhou, "Dynamic radiography using a carbon-nanotube-based fieldemission X-ray source," Rev. Sci. Inst., vol. 75, no. 10, pp. 3264-3267, 2004.

[158] H. Sugie, M. Tanemura, V. Filip, K. Iwata, K. Takahashi, and F. Okuyama, "Carbon nanotubes as electron source in an X-ray tube," Appl. Phys. Lett., vol. 78, no. 17, pp. 2578-2580, 2001.

[159] S. Senda, M. Tanemura, Y. Sakai, Y. Ichikawa, S. Kita, T. Otsuka, A. Haga, and F. Okuyama, "New field-emission X-ray radiography system," Rev. Sci. Ins., vol. 75, no. 5, pp. 1366-1368, 2004.

[160] H. Joseph, B. Swafford, and S. Terry, "MEMS in the medical world," Sens. Mag., vol. 14, pp. 47-51, Apr. 1997.

[161] K. Sakai, "Artificial kidney engineering-dialysis membrane and dialyzer for blood purification,” J. Chem. Eng. Japan, vol. 30, no. 4, pp. 587-599, 1997.

[162] J. Wang, G. Liu, and M. R. Jan, "Ultrasensitive electrical biosensing of proteins and DNA: Carbon-nanotube derived amplification of the recognition and transduction events," J. Amer. Chem. Soc., vol. 126, pp. 3010-3011, 2004.

[163] Y. Xu, Y. Jiang, H. Cai, P. G. He, and Y. Z. Fang, "Electrochemical impedance detection of DNA hybridization based on the formation of M-DNA on ploypyrrole/carbon nanotube modified electrode," Anal. Chim. Acta, vol. 516, pp. 19-27, 2004.

[164] P. He and L. Dai, "Aligned carbon nanotube-DNA electrochemical sensors," Chem. Commun., vol. 3, pp. 348-349, 2004.

[165] O. P. Galaasen. (2002) Nanomedicine and the future of healthcare. Med. Technol. [Online]. Available: http://plausible.custompublish.com/ cparticle54173-5911.html

[166] P. Adrian. (2003) Nanosensors targeted at the right markets could generate big business opportunities. Sens. Bus. Dig. [Online]. Available: http://www.sensorsmag.com/resources/businessdigest/sbd0703.shtml

[167] K. Moloni, A. Lal, and M. Lagally, "Sharpened carbon nanotube probes," Proc. SPIE, vol. 4098, pp. 76-83, 2000.

[168] Y. Nakayama, H. Nishijima, S. Akita, K. I. Hohmura, S. H. Yoshimura, and K. Takeyasu, "Microprocess for fabricating carbon nanotube probes of a scanning probe microscope," J. Vac. Sci. Technol. B: Microelec. Nanomet. Struct., vol. 18, no. 2, pp. 661-664, 2000.

[169] R. M. D. Stevens, N. A. Frederick, B. L. Smith, D. E. Morse, G. D. Stucky, and P. K. Hansma, "Carbon nanotubes as probes for atomic force microscopy," Nanotechnology, vol. 11, no. 1, pp. 1-5, 2000.

[170] C. V. Nguyen, K. J. Chao, R. M. D. Stevens, L. Delzeit, A. Cassell, J. Han, and M. Meyyappan, "Carbon nanotube tip probes: Stability and lateral resolution in scanning probe microscopy and application to surface science in semiconductors," Nanotechnology, vol. 12, no. 3, pp. 363-367, 2001.

[171] Y. N. Emirov, M. Beerbom, D. A. Walters, Z. F. Ren, Z. P. Huang, B. B. Rossie, and R. Schlaf, "Making carbon nanotube probes for high aspect ratio scanning probe metrology," Proc. SPIE, vol. 5038 I, pp. 493-495, 2003.

[172] R. M. D. Stevens, C. V. Nguyen, and M. Meyyappan, "Carbon nanotube scanning probe for imaging in aqueous environment," IEEE Trans. Nanobiosci., vol. 3, no. 1, pp. 56-60, Mar. 2004.

[173] C. V. Nguyen, C. So, R. M. D. Stevens, Y. Li, L. Delzeit, P. Sarrazin, and M. Meyyappan, "High lateral resolution imaging with sharpened tip of multi walled carbon nanotube probe," J. Phys. Chem. B, vol. 108, no. 9, pp. 2816-2821, 2004.

[174] S. Akita, Y. Nakayama, S. Mizooka, Y. Takano, T. Okawa, Y. Miyatake, S. Yamanaka, M. Tsuji, and T. Nosaka, "Nanotweezers consisting of carbon nanotubes operating in an atomic force microscope," Appl. Phys. Lett., vol. 79, no. 11, pp. 1691-1693, 2001.

[175] S. Akita and Y. Nakayama, "Manipulation of nanomaterial by carbon nanotube nanotweezers in scanning probe microscope," Jpn. J. Appl. Phys., vol. 41, no. 6B, pp. 4242-4245, 2002.

[176] P. Kim and C. M. Lieber, "Nanotube nanotweezers," Science, vol. 286, pp. 2148-2150, 1999.

[177] R. A. Freitas Jr., "The future of nanofabrication and molecular scale devices in nanomedicine," Stud. Health Technol. Inf., vol. 80, pp. 45-59, 2002.

[178] S. J. Tans, M. H. Devoret, H. Dai, A. Thess, R. E. Smalley, L. J. Geerligs, and C. Dekker, "Individual single-wall carbon nanotubes as quantum wires," Nature, vol. 386, pp. 474-477, 1997.

[179] M. Bockrath, D. H. Cobden, P. L. McEuen, N. G. Chopra, A. Zettle, A. Thess, and R. E. Smalley, "Single-electron transport in ropes of carbon nanotubes," Science, vol. 275, no. 5308, pp. 1922-1925, 1997.

[180] M. R. Buitelaar, A. Bachtold, T. Nussbaumer, M. Iqbal, and C. Schonenberger, "Multiwall carbon nanotubes as quantum dots," Phys. Rev. Lett., vol. 88 , no. 15 , p. $156801,2002$. 
[181] A. Nojeh, G. W. Lakatos, S. Peng, K. Cho, and R. F. W. Pease, “A carbon nanotube cross structure as a nanoscale quantum device," Nano Lett., vol. 3, no. 9, pp. 1187-1190, 2003.

[182] Y. T. Lim, S. Kim, A. Nakayama, N. E. Stott, M. G. Bawendi, and J. V. Frangioni, "Selection of quantum dot wavelengths for biomedical assays and imaging," Mol. Imaging, vol. 2, no. 1, pp. 50-64, 2003.

[183] K. Park, Controlled Drug Delivery: Challenges and Strategies. Washington, DC: American Chemical Society, 1997.

[184] (2003, Feb.) Briefing Paper: Inst. Neurosci. Mental Health and Addiction. CIHR. [Online]. Available: http://www.regenerativemedicine.ca/nanomed/Nanomedicine\%20Taxonomy\%20(Feb\%202003).PDF

[185] C. R. Martin and P. Kohli, "The emerging field of nanotube biotechnology," Nature Rev.: Drug Discovery, vol. 2, pp. 29-37, 2003.

[186] D. Pantarotto, J. P. Briand, M. Prato, and A. Bianco, "Translocation of bioactive peptides across cell membranes by carbon nanotubes," Chem. Commun., vol. 1, pp. 16-17, 2004.

[187] D. Penman. (2003) Carbon nanotubes show drug delivery promise. NewScientist.Com News Service [Online]. Available: http://www. newscientist.com/article.ns?id=dn4485\&print=true

[188] H. Gao, Y. Kong, D. Cui, and C. Z. Ozkan, "Spontaneous insertion of DNA oligonucleotides into carbon nanotubes," Nano Lett., vol. 3, no. 4, pp. 471-473, 2003.

[189] Y. Kong, D. Cui, C. S. Ozkan, and H. Gao, "Modeling carbon nanotube based bio-nano systems: A molecular dynamics study," in Proc. Materials Research Soc. Symp., vol. 773, 2003, pp. 111-116.

[190] W. L. Jorgensen, "The many roles of computation in drug discovery," Science, vol. 303, pp. 1813-1818, 2004.

[191] A. Bhargava. (1999) Nanorobots: Medicine of the future. [Online]. Available: http://www.ewh.ieee.org/r10/Bombay/news3/page4.html

[192] M. C. Shults, R. K. Rhodes, S. J. Updike, B. J. Gilligan, and W. N. Reining, "A telemetry-instrumentation system for monitoring multiple subcutaneously implanted glucose sensors," IEEE Trans. Biomed. Eng., vol. 41, no. 10, pp. 937-942, Oct. 1994.

[193] A. Bolz, V. Lang, B. Merkely, and M. Schaldach, "First results of an implantable sensor for blood flow measurement," in Proc. Annu. Int. Conf. IEEE Engineering in Medicine and Biology Soc., vol. 5, 1997, pp. 2341-2343.

[194] R. Shandas and C. Lanning, "Development and validation of implantable sensors for monitoring function of prosthetic heart valves: in vitro studies," Med. Biol. Eng. Comp., vol. 41, no. 4, pp. 416-424, 2003.

[195] G. Kiernan, V. Barron, D. Blond, A. Drury, J. Coleman, R. Murphy, M. Cadek, and W. Blau, "Characterization of nanotube based artificial muscles materials," Proc. SPIE, vol. 4876, no. 2, pp. 775-782, 2002.

[196] Y. Gogotsi, J. A. Libera, A. G. Yazicioglu, and C. M. Megaridis, "In situ multiphase fluid experiments in hydrothermal carbon nanotubes," Appl. Phys. Lett., vol. 79, no. 7, pp. 1021-1023, 2001.
[197] C. M. Megaridis, A. G. Yazicioglu, J. A. Libera, and Y. Gogotsi, "Attoliter fluid experiments in individual closed-end carbon nanotubes: Liquid film and fluid interface dynamics," Phys. Fluids, vol. 14, no. 2, pp. L5-L8, 2002.

[198] K. E. Drexler, Nanosystems: Molecular Machinery, Manufacturing, and Computation. New York: Wiley, 1992.

[199] J. Cumings and A. Zettle, "Low-friction nanoscale linear bearing realized from multiwall carbon nanotubes," Science, vol. 289, pp. 602-604, 2000.

[200] M. S. Dresselhaus and H. Dai, "Carbon nanotubes: Continued innovations and challenges," MRS Bull.: Adv. Carbon Nanotubes, vol. 29, no. 4, pp. 237-243, 2004.

[201] R. Dagani, "Nanomaterials: Safe or unsafe?," Chem. Eng. News, vol. 81, no. 17 , pp. 30-33, 2003.

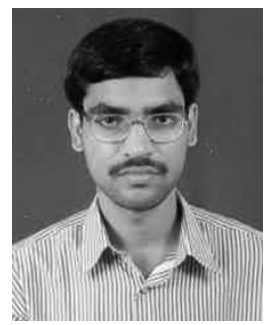

Niraj Sinha (S'05) received the B.Tech. degree in manufacturing engineering from NIFFT, Ranchi, India, in 2000 and the M.Sc. degree in mechanical engineering from the University of Saskatchewan, Saskatoon, SK, Canada, in 2004. He is currently working toward the Ph.D. degree in the department of systems design engineering at University of Waterloo, Waterloo, ON, Canada.

His current research interests are in the field of developing biomedical instruments using carbon nanotubes.

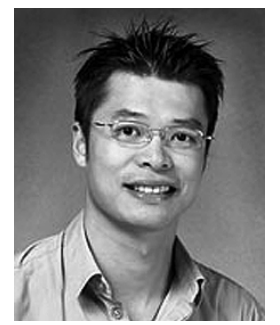

John T.-W. Yeow (M'04) received the B.A.Sc. degree in electrical and computer engineering and the M.A.Sc. and PhD. degrees in mechanical and industrial engineering from the University of Toronto, Toronto, ON, Canada, in 1997, 1999, and 2003, respectively.

He is currently a Faculty Member in the Department of Systems Design Engineering at University of Waterloo, Waterloo, ON, Canada. His current research interests are in the field of developing novel microelectromechanical systems (MEMS)/nanoelectromechical systems (NEMS) devices for biomedical imaging, biosensors, environmental sensors, microfluidic devices, and developing next-generation biomedical instruments using carbon nanotubes. 